\title{
Leaving Boys Behind Gender Disparities in High Academic Achievement
}

\author{
Nicole M. Fortin \\ Philip Oreopoulos \\ Shelley Phipps
}

\begin{abstract}
Using data from the "Monitoring the Future" surveys, this paper shows that from the 1980s to the 2000s, the mode of girls' high school GPA distribution has shifted from " $B$ " to " $A$," essentially "leaving boys behind" as the mode of boys' GPA distribution stayed at " $B$." In a reweighted Oaxaca-Blinder decomposition of achievement at each GPA level, we find that changes to gender differences in post-secondary expectations, in particular expectations for attending graduate or professional school, are the most important factors accounting for this trend after controlling for school ability and they occur as early as the eighth grade.
\end{abstract}

\section{Introduction}

Women now far outnumber men among recent college graduates in most industrialized countries (Vincent-Lancrin 2008). As Goldin, Katz, and Kuziemko

Nicole Fortin is professor of economics at the Vancouver School of Economics, University of British Columbia. Philip Oreopoulos is professor of economics at the University of Toronto. Shelley Phipps is professor of economics at Dalhousie University. All co-authors are Senior Research Fellows at the Canadian Institute for Advanced Research.

They would like to acknowledge Lori Timmins for her outstanding research assistance on this project. They would also like to thank Jerome Adda, Joseph Altonji, Marianne Bertrand, Russell Cooper, David Card, Steve Durlauf, Christian Dustmann, Andrea Ichino, Claudia Goldin, Larry Katz, John Kennan, Magne Mogstad, Mario Small, Uta Schonberg, Chris Taber, Thomas Lemieux, Glen Waddell, Ian Walker, Basif Zafar, and seminar participants at Bocconi University, Einaudi Institute for Economics and Finance, European University Institute, Federal Reserve Bank of New York, Harvard University, Norwegian School of Business and Economics, Paris I, Sciences Po, University College London, University of Oregon, University of Wisconsin-Madison, Yale University, the CEA 2011, the CIFAR SIIWB Workshop, the NBER Summer Institute 2013, and SOLE 2012 for helpful comments on this and earlier versions of the manuscript. They thank ICPSR and MTF for allowing them to use the data, and the usual disclaimer applies. The authors are grateful for CIFAR's financial support. Fortin also acknowledges funding from SSHRC Grants \#410-2011-0567. The data used in this article can be obtained beginning January 2016 through December 2019 from Nicole Fortin, Vancouver School of Economics, University of British Columbia, Vancouver, BC,V6T 1W1,nicole.fortin@ubc.ca.

[Submitted August 2012; accepted April 2014]

ISSN 0022-166X E-ISSN 1548-8004 (C) 2015 by the Board of Regents of the University of Wisconsin System This open access article is distributed under the terms of the CC-BY-NC-ND license (http://creativecommons.org/ licenses/by-nc-nd/3.0) and is freely available online at: http://jhr.uwpress.org

THE JOURNAL OF HUMAN RESOURCES • 50 • 3 
(2006) observe, the puzzle is: "Why have women overtaken men in terms of college completion instead of simply catching up to them?" The growing female dominance in educational attainment raises new questions about gender disparities arising throughout school ages. ${ }^{1}$ This paper addresses two questions: (1) Are boys and girls equally well prepared and focused on going to college? and (2) What accounts for the growing gender disparity in favor of girls obtaining high grades in secondary school?

Our first goal is to document changes in gender disparities in the academic performance of secondary school students (twelfth and eighth graders) over the last three decades using survey data from the "Monitoring the Future" (MTF) project. ${ }^{2}$ Girls have long obtained better grades in high school, on average, than boys. As shown in Figure 1a, the average gender gap in GPA among high school seniors (scaled out of four points) hovers steadily around 0.2 between 1976 and 2009. However, we find that over time an increasing proportion of students are earning A grades, arguably allowed by the progressive disaffection with "grading on a curve."4 As shown in Figure 1b, the percentage of twelfth grade students reporting in the MTF that they earn As (93-100 percent) almost doubled, from 8.5 percent in the 1980 s to 16.6 percent in the $2000 \mathrm{~s}$, and the difference between the proportion female and the proportion male in this category also doubled from 3.2 percent to 5.4 percent. ${ }^{5}$ From the 1990 s to the 2000 s, the female advantage in the proportion of eighth graders earning As also increased from 4.9 to 5.5 percentage points.

Our second goal is to identify the relative importance of four sets of factors that changed differently by gender over time and that could account for this growing gender disparity in academic achievement. These include plans for the future, noncognitive skills, the family environment, and working while in school. The post-secondary aspirations and expectations of high school students, as well as their choice of high school program (from vocational to academic) to enact these career plans, are the set of factors - called "plans for the future" - that changed the most over the last three decades. It is well known that returns to college have risen faster for men than for women over that period. ${ }^{6}$ Figure $2 \mathrm{a}$ shows that just the opposite happened to expectations about "definitively" attending a graduate or professional school after college. Among seniors, boys' expectations about attending graduate school were slightly higher than girls' from 1976 to 1983 but thereafter a gap in favor of girls began to emerge. In the early 1990s, following the computer revolution of the 1980 s, the gap began to widen substantially, reaching nine percentage points before the Great Recession. Figure $2 \mathrm{~b}$ presents the gender ratio among students who answer that

1. See for example, LoGerfo, Nichols, and Chaplin (2006); Machin and McNally (2005); Bertrand and Pan (2013).

2. To the best of our knowledge, Jacob and Wilder (2012) is the only other contemporaneous paper using the MTF to study educational expectations. They study the impact of these expectations on going to college. In Fortin, Oreopoulos, and Phipps (2013), we study the outcomes of tenth graders as well.

3. The gender gap in GPA from the MTF match (within standard errors) the numbers from the National Assessment of Educational Progress (NAEP) High School Transcript Study for 1990, 2000, 2005, and 2009, reported in Perkins et al. (2004), as well as the numbers reported in Cho (2007) for 1984 from the High School and Beyond survey.

4. To be clear, the erosion of grading on a curve is not seen as "causing" an increasing proportion of girls to earn As, rather the absence of constraints on the proportion of students earnings As implies that we do not have to be preoccupied by potential general equilibrium effects that such constraints would imply.

5. In the MTF, an A grade corresponds to a percentile grade in the $93-100$ percent range. To facilitate the exposition, we regroup our data for seniors into three time periods of 10-12 years, 1976-88, 1989-99, and 2000-2009, rather than the four decades. The exact years are 1991-99 for the 1990s for eighth graders.

6. See Charles and Luoh (2003), Fortin (2006). 
A. Average Grades
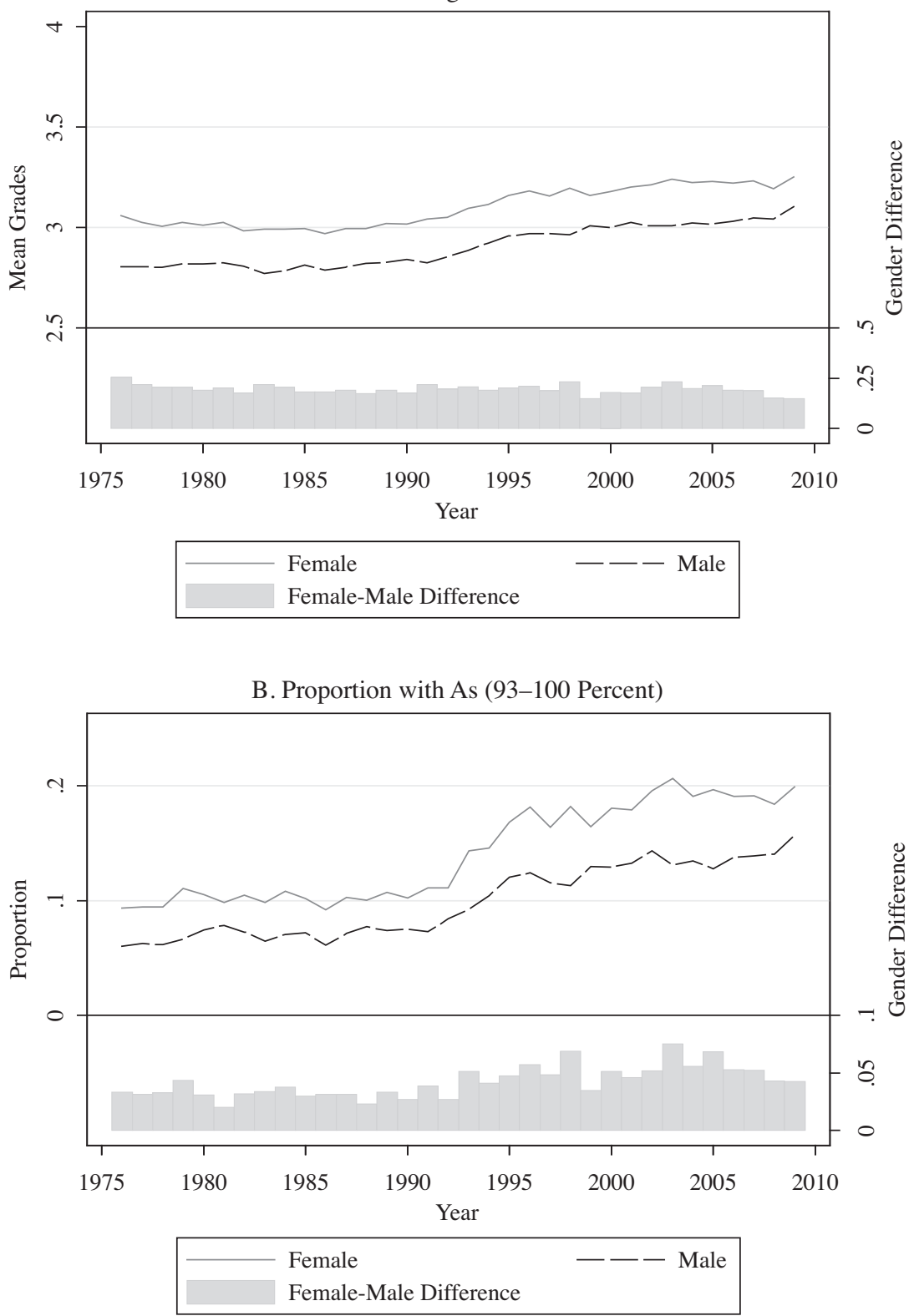

\section{Figure 1}

Self-Reported Grades of High School Seniors by Gender

Notes: In top panel, self-reported grades in nine categories (D, C-, C, C+, B-, B, B+, A-, A) are translated into the numbers $1,1.7,2,2.3,2.7,3,3.3,3.7$, and 4 following standard institutional practice. 

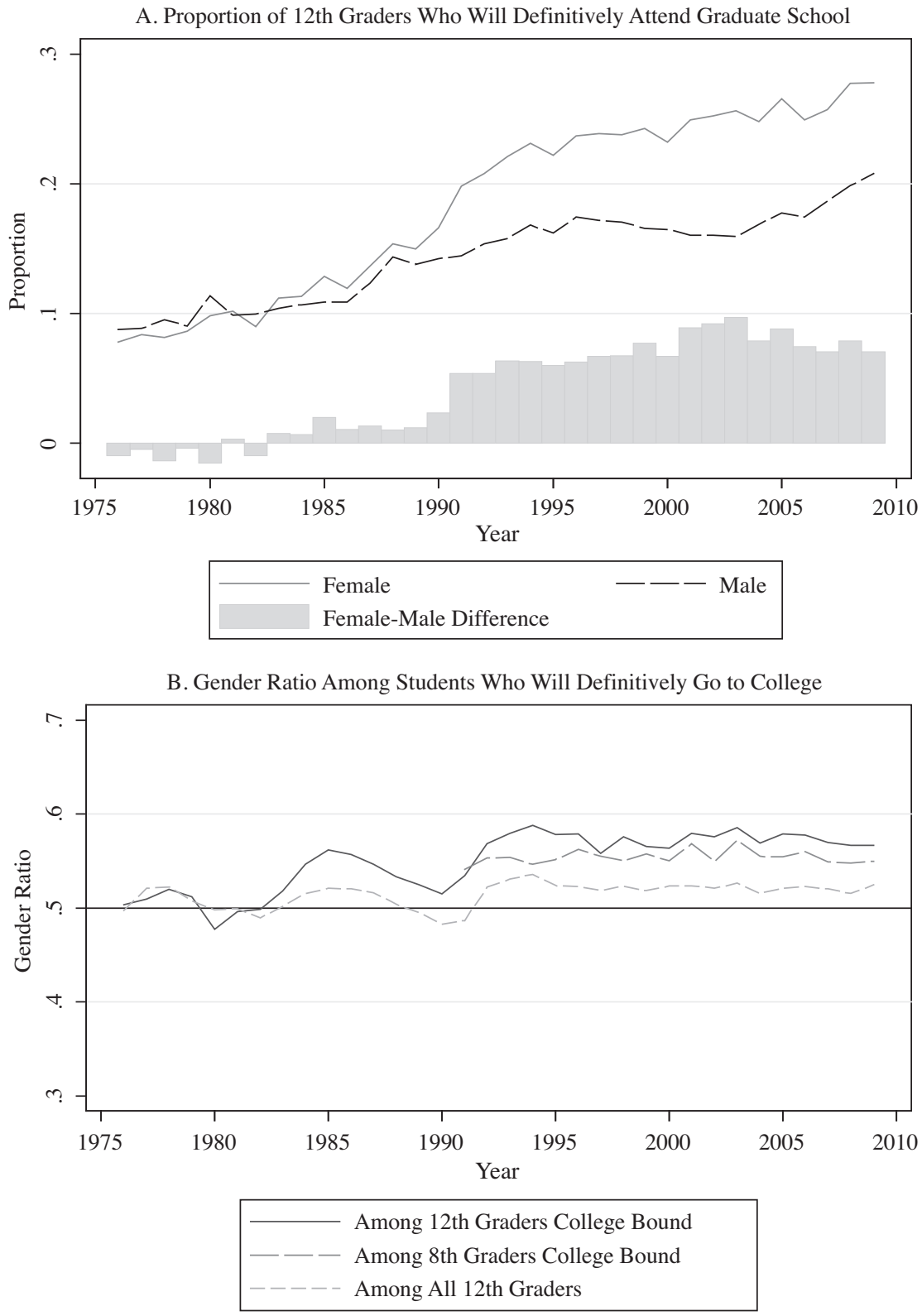

\section{Figure 2}

Educational Expectations of High School Students 
they "will definitively go to a four year college." Among seniors, the gender ratio (female share) was around 50 percent up to the early 1980 s, overshot the gender ratio in actual enrollment rates by a few percentage points in the 1990s, to stabilize around 57 percent in the 2000s; this corresponds to an excess 5 percent of girls given the 52 percent gender ratio among seniors. ${ }^{7}$ The gender ratio in expectations about attending a four-year college emerges as early as Grade 8, when it hovers around 55 percent.

Goldin and Katz (2002) have argued that the 1970s "Pill Revolution" was crucial in allowing young women to formulate plans for higher education without the fear of interruptions for family reasons. We find that in subsequent decades young women's career plans increasingly involve professional and graduate schools and that clerical jobs have completely lost their appeal. ${ }^{8}$ Table 1 displays the dramatic changes in the vocational expectations of high school seniors (available only for a subsample). The percentage of girls thinking that they will be working at age 30 in a professional job requiring a post-graduate degree (doctoral or equivalent) climbed from 15.3 percent in the 1980s to 27.1 percent in the 2000s; for boys the change was from 13.5 to 16.4 percent. With the advent of computerization and other office technologies, there has been a substantial decline in labor market demand for clerical work matched by the decline in vocational expectations: The percentage of girls expecting to work in a clerical job at age 30 has plummeted from 21 percent in the 1980 s to less than 3 percent in the 2000 s. ${ }^{9}$ This sharp decline is not matched by as great a decline in skilled and semiskilled work, craftsmanship, and protective services as expected occupations for boys. Autor and Wasserman (2013) also argue that men have adapted less successfully than women to new labor market conditions. For our complete sample, our educational expectation variables include a full range of "plans for life after high school," such as serving in the army, attending a vocational college, a two-year college, a four-year college, and aiming for graduate or professional school.

The data do not allow us to consider the effect from changes in teaching styles (Algan, Cahuc, and Shleifer 2010) or changes in teachers' gender (Dee 2005) that have attracted recent attention. We do, however, include information on the types of high school program (academic, vocational, general, etc.) attended, which are associated with different GPA distributions. ${ }^{10}$ Following the wave of interest in the impact of noncognitive traits, we account for smoking, alcohol binging, and school misbehavior. ${ }^{11}$ The other sets of factors that we consider are the family environment and working during school. Families with girls are, on average, larger (consistent with Angrist and

\footnotetext{
7. Appendix Figures A2a and A2b in Fortin, Oreopoulos. and Phipps (2013) illustrate how the see-saw pattern of the 1980s in Figure $2 \mathrm{~b}$ arises from the changes in family planning methods 18 years earlier and the fact that boys are more likely than girls to repeat grades.

8. While we argue that changes in the labor market are likely the most important factors behind the changes in expectations, we cannot rule out the possible effect of changes in expectations about the likelihood of divorce. 9. Data from the Current Population Survey show that the actual proportion of young women (25-39 years old) employed in clerical work has dropped by 9 percent over the 35 -year period while the proportion employed in professional occupations has increased by 9 percent (see Table A1 in Fortin, Oreopoulos, and Phipps 2013). 10. Similar information on the types of high school program (academic, general, vocational, etc.) in which students are enrolled is also asked in the NLS72 and NELS-88, for example.

11. Some psychologists (for example, Duckworth and Seligman 2006) have argued that self-control and selfdiscipline give girls the "edge." We attempt to capture a similar notion with the "alcohol binging" variable. The gender gap in smoking, which had closed in the 1970s and early 1980s, has reopened more recently. The information on the frequency of being sent to the principal or to detention for bad behavior in the last year is only available for tenth and eighth graders. School misbehavior, which has decreased over time for boys, has reduced the gender gap in misconduct. See Fortin, Oreopoulos, and Phipps (2013), Figure A1.
} 
$n$
0
n
0
00
0
0
0
0
0
0
0
0
0
0
0
0
0
0
0
0.0
0
0
0
0
0
0
0
0
0
0
0
0
0

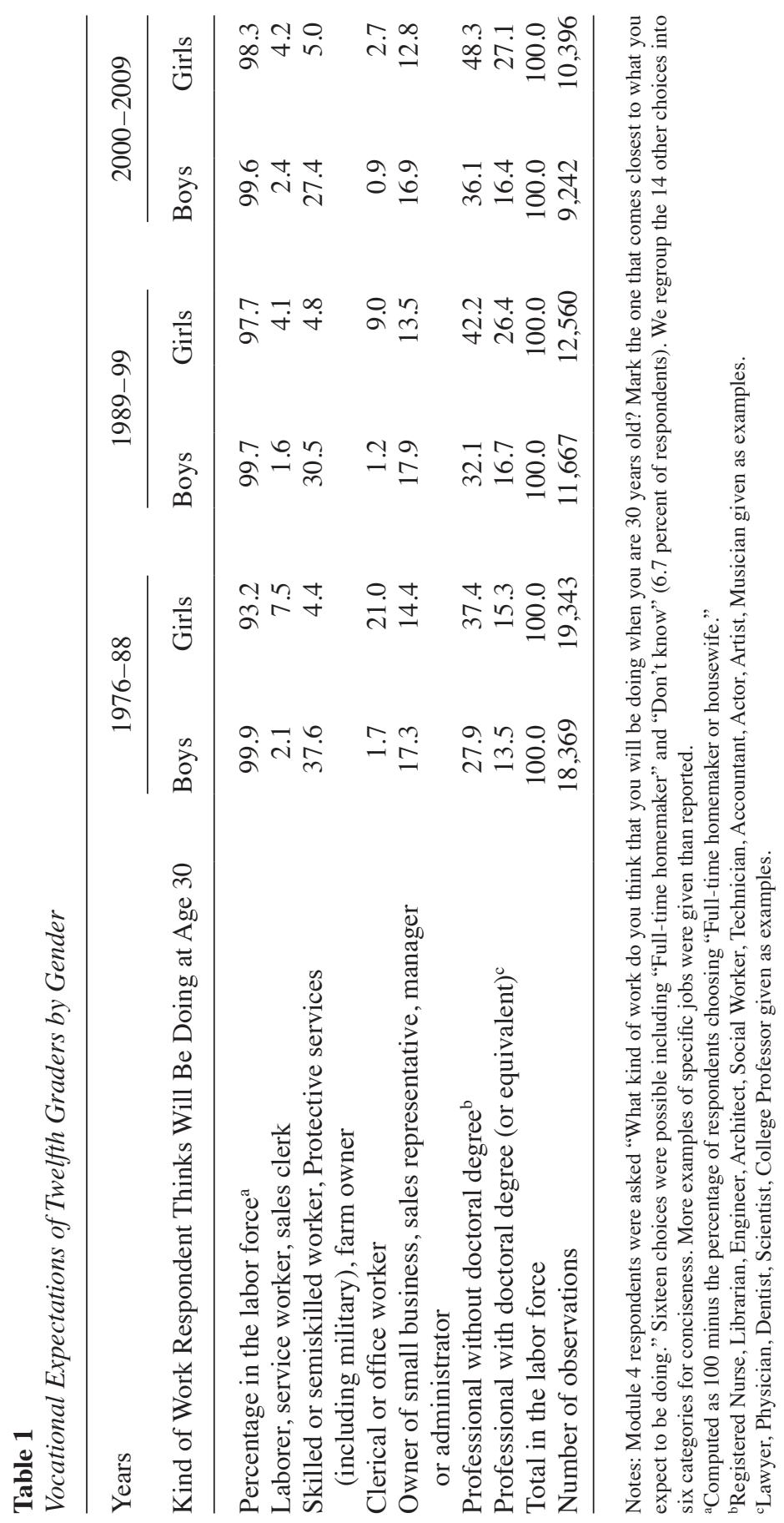


Evans 1998), have less-educated parents, more working mothers, and more fathers not living in the same household (see Dahl and Moretti 2008). These last two gender gaps in family characteristics are increasing over time. Finally, a decline in the labor force participation of boys during school, from 85 percent in the 1980 s to 76 percent in the 2000s, has led to a closing of the gender gap in market work during high school.

We focus on an analysis of changes over time in the distribution of GPA because gender differences in average GPA have not changed over the past 30 years while the gender ratio of students admitted to college, those with high GPA, has changed substantially. As with most studies of changes in gender differentials, we construct counterfactual states of the world based on the observed responses (estimated coefficients) and respective endowments of males and females. We use the reweighted decomposition methodology (Fortin, Lemieux, and Firpo 2011) to separate endowment effects from response effects. More precisely, we construct a counterfactual sample of boys reweighted to have the same characteristics as girls. We then make the assumption that the distribution of unobservables, conditioning on observables, is independent of gender. Then differences between the educational responses from this counterfactual sample and those of girls reflect true gender differences in educational responses (rather than misspecification error because the underlying conditional expectation is nonlinear).

Our decomposition of the impact of educational expectations on GPA may only be interpreted as a direct effect if the distribution of unobservables conditional on observables is independent of gender. To explore whether changes in other factors, such as ability, returns to college, or financial constraints, underlie changes in expectations, we use data from the MTF surveys on educational aspirations and subjective assessments of school ability. This allows us to consider indirect effects and to present bounds on the direct effects of educational expectations with and without these controls. With respect to the possibility of reverse causality, where changes to GPA distribution may affect education aspirations, we note that the sudden 1991 rise in the expectations of girls about pursuing a professional or graduate degree (Figure 2b) preceded and exceeded in size the 1993 marked rise in the proportion of girls obtaining As (Figure 1b). That being said, our analysis uses selection on observables for identifying explanatory factors behind changes in educational aspirations rather than a quasi-experimental or experimental design. ${ }^{12}$

The rest of the paper is organized as follows. Section II introduces the MTF surveys and presents some descriptive statistics about gender disparities in academic achievement and in the explanatory factors. Section III presents our empirical specification and explains the reweighted decomposition methodology. Section IV presents the decomposition results and discusses their interpretation. Finally, Section V concludes.

\section{Data and Descriptive Statistics}

The data used are from the "Monitoring the Future" surveys that were conducted by University of Michigan's Institute for Social Research mainly to monitor

12. As reported in Ford (2012) and Frenette et al. (2012), two experimental "Future to Discover" interventions, which promised nonrepayable financial aid to students from low-income families and which provided high school students with enhanced career education, generally had much larger impacts on boys' post-secondary attendance, raising their attendance to match that of girls, which was already high. This is consistent with our findings. 
substance abuse every year from 1976 onward for Grade 12 students and from 1991 onward for students in Grade $8 .{ }^{13}$ Given higher male dropout rates, our sample of twelfth graders is only 48 to 49 percent male. Thus, our sample of seniors likely comprises a positively selected sample of boys, leading us to understate any gender gap favorable to girls by comparison to a wider sample of boys. It is thus useful to compare high school seniors with eighth graders, who remain subject to minimum age school leaving laws. We focus on the core sample, which is comprised of 10,000 to 16,000 observations per grade per year, and allows us to perform the breakdown by gender and GPA. ${ }^{14}$

Our dependent variable is the self-reported school grade that is elicited from the following question: "Core 20: Which of the following best describes your average grade so far in high school? D (69 or below), C- (70-72), C (73-76), C+ (77-79), B- (80-82), B (83-86), B+ (87-89), A- (90-92), A (93-100)."15 Obviously, grades from administrative data are preferable to self-reported grades because students with different characteristics may misreport their grades differently. ${ }^{16}$ But we find that the self-reported grades from the MTF are very reliable. ${ }^{17}$ When we compare the average grades of twelfth graders from the MTF to those of the High School Transcript Surveys (HSTS) of the NAEP (reported in Perkins et al. 2004) we find that the gender differences, as well as the grade inflation, do match within standard errors, even though the scales used are somewhat different. ${ }^{18}$ Note that this report finds, as Goldin, Katz, and Kuziemko (2006) also reported, that girls are increasingly taking more challenging math and science courses. Card, Payne, and Sechel (2011) find that the 10 percentage gender gap (female advantage) in university application rates of Ontario students is very strongly related to the fraction of students who take the academic versus applied mathematics test in Grade 9.

There are other questions in the MTF survey of seniors, asked before this one and directed at getting subjective assessments of school ability (Core 16) and intelligence (Core 17), which would allow students who are so inclined to boast about their abilities. The question on subjective school ability asks: "Core 16: Compared with others your age throughout the country how do you rate yourself on school ability? Far below average, below average, slightly below average, average, slightly above average,

13. Because of the focus on drug use, those who use illicit drugs as seniors are oversampled; we are careful to use the sample weights provided to remove any bias resulting from that oversampling. There exists a seldom accessed longitudinal component, which surveys a small subset of the students (Bachman et al. 2002). 14. Many more attitudes and behavioral questions are asked of students answering one of six modules, including a host of noncognitive variables, but they are asked only of a subset of students.

15. Following standard institutional practice, the self-reported grades in the nine categories are translated in the numbers: A (93-100) 4.0, A- (90-92) 3.7, B+ (87-89) 3.3, B (83-86) 3.0, B- (80-82) 2.7, C+ (77-79) $2.3, \mathrm{C}(73-76) 2, \mathrm{C}-(70-72) 1.7, \mathrm{D}$ (69 or below) 1 , where 2.3 and 2.7 and so on are the rounded versions of 2.333 and 2.666 .

16. See Balsaa, Giuliano, and French (2011) on grade misreporting by alcohol binging students.

17. The wording of the question on self-reported grades in terms of an upward scale is similar to commonly used questions about self-reported income where individuals are asked to declare in which income bracket their income falls and may be less prone to error than simple declarative questions.

18. The HSTS scale has five categories, which include a zero: A (90-100) 4.0, B (80-89) 3.0, C (70-79) 2.0, D (60-69) 1.0, F (less than 60) 0.0 . 
above average, far above average."19 Boys and girls, on average, provide the same subjective ratings of their school ability but boys rate themselves more favorably on intelligence than do girls. ${ }^{20}$ We note that the raw correlation between subjective school ability and self-reported grades is only 58 percent among seniors.

Table 2 begins by reporting a simple difference-in-difference analysis of the changes over time and by gender in self-reported grades and in expectations about attending graduate or professional school of twelfth graders. Like Figure 1, Panel A of Table 2 shows little change over time in the significant female advantage of about 0.2 (on a four point scale) in average grades; if anything, boys have made small gains (about 0.01 ) in relative grades. Panel B shows that the stability in average grades masks a significant increase in the female advantage in the proportion of students with the highest grades (A [93-100] students), which represents the pool of students that can be confident of being admitted to graduate school if they continue to succeed in their undergraduate studies. Our focus on the gender gap in top grades follows from the findings of previous studies (Jacob 2002; Goldin, Katz, and Kuziemko 2006; Cho 2007; Conger and Long 2010) showing that the lower college admission rates of men can in large part be accounted for by their lower high school performance. ${ }^{21}$ However, better high school performance explains "how" more girls are admitted to college but not "why."

As in Figure 2a, Panel $\mathrm{C}$ of Table 1 shows an even greater and significant increase of the female advantage in expectations of attending professional or graduate school. Indeed, from the 1980 s to 1990 s, the proportion of women expecting to attend graduate school more than doubled from 10 percent to 21 percent while the proportion of men increased only by half, from 10 percent to 15 percent. The fact that the increase in the gender differential in expectations to attend graduate school was more sizeable (5.3 percentage points) from the 1980 s to the 1990 s, when women's progress in the labor market was sharpest, than from the 1990s to the 2000s (2.6 percentage points) are in line with our conjecture that gender differences in plans for the future fuel gender differences in high academic achievement. But we do not claim to have firm evidence on the causes of the changes in educational expectations.

A more complete picture of changes in academic achievement is presented in Figure 3 , which displays histograms corresponding to the actual data overlaid with a kernel density of the self-reported grades of girls and boys in twelfth grade. The figures clearly show a progressive disaffection over the past 35 years with "grading on a curve," with the alternative "competency grading" gaining in importance. ${ }^{22}$ In the 1980 s, the mode

19. As with the other categorical variables, we rescale this variable to be between 0 and 1 using the following formula: Category $k=1-(n-k+1) /(n+1)$, when $k=n$ is highest category to be recoded into 1 . This recoding presumes equal distance between the categories.

20. The question on intelligence asks on the same seven point scale: "Core 17: How intelligent do you think you are compared with others your age?" See Fortin, Oreopoulos, and Phipps (2013), Figures A3a and A3b.

21. The higher average grades of girls are at times equated with their higher average noncognitive abilities (Jacob 2002; Becker, Hubbard, and Murphy 2010). Alternatively, Cornwell, Mustard, and Van Parys (2013) argue that discrepancies between test scores and grades by gender are due to discrimination by teachers. If teachers discriminate on the basis of classroom behavior rather than pure gender preference, grades would incorporate some noncognitive abilities.

22. "Grading on a curve" means grading relatively to classmates, whereas "competency grading" means that if a student's work deserves an A for example, the student should get an A irrespective of the number of classmates getting As. 
Table 2

Difference-and-Differences Estimates in Academic Performance and Plans for the Future - Twelfth Graders

\begin{tabular}{|c|c|c|c|c|c|c|}
\hline Time Period & $\begin{array}{c}1976-88 \\
(1)\end{array}$ & $\begin{array}{c}\text { 1989-99 } \\
\text { (2) }\end{array}$ & $\begin{array}{c}\text { Change } \\
\text { over } \\
\text { Time } \\
(2)-(1) \\
(3)\end{array}$ & $\begin{array}{c}2000-2009 \\
\text { (4) }\end{array}$ & $\begin{array}{c}\text { Change } \\
\text { over } \\
\text { Time } \\
(4)-(2) \\
(5)\end{array}$ & $\begin{array}{c}\text { Change } \\
\text { over } \\
\text { Time } \\
(4)-(1) \\
(6)\end{array}$ \\
\hline \multicolumn{7}{|c|}{ A: Average grades } \\
\hline Girls & $\begin{array}{c}\mathbf{3 . 0 0 4} \\
(0.002)\end{array}$ & $\begin{array}{c}\mathbf{3 . 1 0 6} \\
(0.002)\end{array}$ & $\begin{array}{c}0.102 \\
(0.003)\end{array}$ & $\begin{array}{c}\mathbf{3 . 2 1 8} \\
(0.003)\end{array}$ & $\begin{array}{c}0.112 \\
(0.003)\end{array}$ & $\begin{array}{c}0.214 \\
(0.003)\end{array}$ \\
\hline Boys & $\begin{array}{c}\mathbf{2 . 8 0 4} \\
(0.002)\end{array}$ & $\begin{array}{c}\mathbf{2 . 9 0 7} \\
(0.002)\end{array}$ & $\begin{array}{c}0.103 \\
(0.003)\end{array}$ & $\begin{array}{c}\mathbf{3 . 0 3 0} \\
(0.003)\end{array}$ & $\begin{array}{c}0.123 \\
(0.004)\end{array}$ & $\begin{array}{c}0.225 \\
(0.003)\end{array}$ \\
\hline Difference & $\begin{array}{c}0.200 \\
(0.003)\end{array}$ & $\begin{array}{c}0.199 \\
(0.003)\end{array}$ & $\begin{array}{c}-0.001 \\
(0.004)\end{array}$ & $\begin{array}{c}0.189 \\
(0.004)\end{array}$ & $\begin{array}{c}-0.010 \\
(0.005)\end{array}$ & $\begin{array}{c}-0.011 \\
(0.005)\end{array}$ \\
\hline
\end{tabular}

$\begin{array}{lcccccc}\text { Girls } & \mathbf{0 . 1 0 0} & \mathbf{0 . 1 4 3} & 0.043 & \mathbf{0 . 1 9 2} & 0.048 & 0.091 \\ & (0.001) & (0.004) & (0.001) & (0.004) & (0.002) & (0.002) \\ \text { Boys } & \mathbf{0 . 0 6 9} & \mathbf{0 . 0 9 9} & 0.030 & \mathbf{0 . 1 3 7} & 0.038 & 0.068 \\ & (0.001) & (0.001) & (0.001) & (0.001) & (0.002) & (0.001) \\ \text { Difference } & 0.032 & 0.044 & 0.012 & 0.054 & 0.011 & 0.023 \\ & (0.002) & (0.002) & (0.002) & (0.003) & (0.003) & (0.002)\end{array}$

C: Proportion definitely will attend graduate or professional school ${ }^{\mathrm{a}}$

\begin{tabular}{lcccccc} 
Girls & $\mathbf{0 . 1 0 1}$ & $\mathbf{0 . 2 0 5}$ & 0.104 & $\mathbf{0 . 2 4 9}$ & 0.044 & 0.147 \\
& $(0.001)$ & $(0.001)$ & $(0.002)$ & $(0.002)$ & $(0.002)$ & $(0.002)$ \\
Boys & $\mathbf{0 . 0 9 9}$ & $\mathbf{0 . 1 5 0}$ & 0.051 & $\mathbf{0 . 1 6 8}$ & 0.018 & 0.069 \\
& $(0.001)$ & $(0.001)$ & $(0.002)$ & $(0.001)$ & $(0.002)$ & $(0.002)$ \\
Difference & 0.003 & 0.055 & 0.053 & 0.081 & 0.026 & 0.078 \\
& $(0.002)$ & $(0.002)$ & $(0.002)$ & $(0.003)$ & $(0.003)$ & $(0.002)$ \\
Number of & 207,152 & 160,403 & & 118,173 & & \\
observations & & & & & & \\
\hline
\end{tabular}

Notes: Self-reported grades in nine categories (D, C-, C, C+, B-, B, B+, A-, A) are translated into the numbers $1,1.7,2,2.3,2.7,3,3.3,3.7$, and 4 following standard institutional practice.

aThe numbers for other post-secondary choices are reported in Table 3.

and median of the grades distribution roughly coincided in the B range. By the 2000s, the mode of the girls' grade distribution had moved from B to A, while the mode of the boys' grade distribution stayed at B. ${ }^{23}$ This is what we call "leaving boys behind"; although the proportion of boys in the A range has increased over time, the gender gap in the proportion of students at the very top of the GPA distribution has increased.

23. Similar gender differences can be found in the administrative grades available in the Add Health data, for example. 

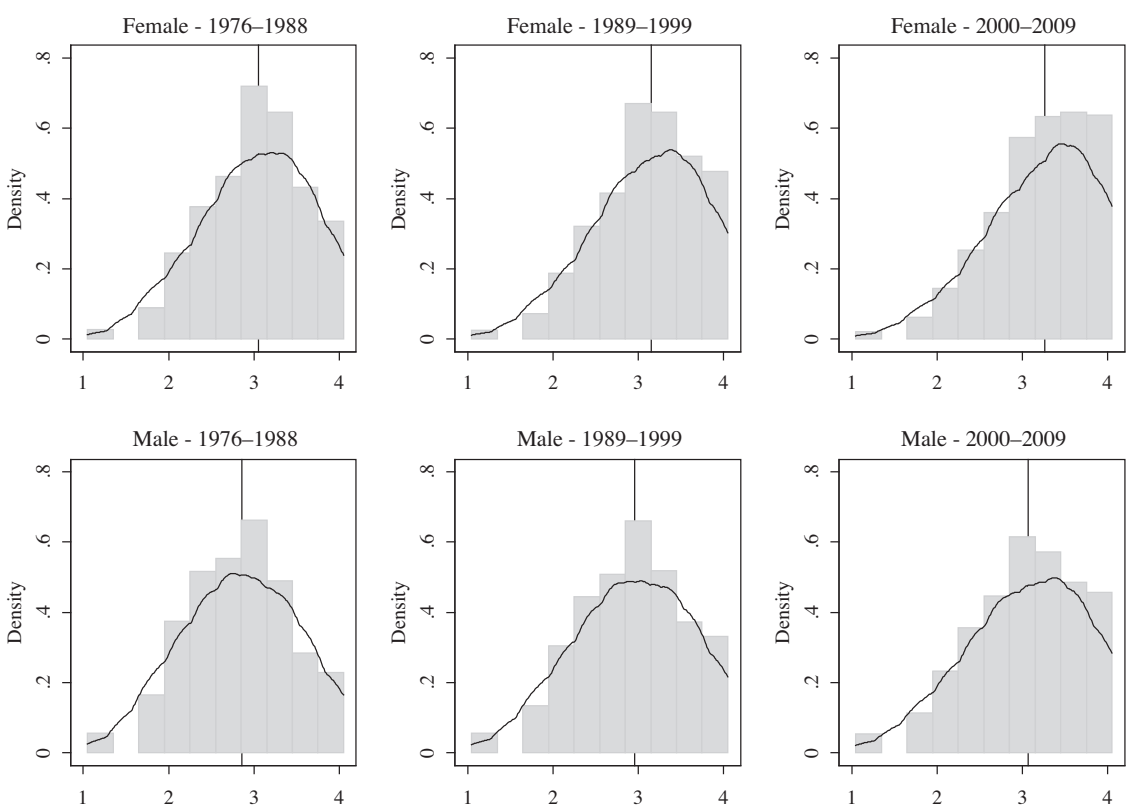

\section{Figure 3}

\section{Male and Female Densities of Self-Reported Grades Among Twelfth Graders}

Notes: Average grades are indicated by vertical line. Histogram that corresponds to actual data is overlaid with a kernel density.

Figure 4 reports the same data on eighth graders for two time periods, 1991-99 and 2000-2009. Here, the girls' advantage appears even more dramatic.

One may wonder whether these distributional changes arise from increases in the mean grade pushing the upper tail against the upper boundary or from increases in the upper tail pulling the mean. With the first hypothesis, the explanations behind the increases in mean grade remain unspecified under the heading "grade inflation." We test this hypothesis by first estimating an ordered probit of GPA levels for the three time periods and then using the estimated cutoffs of the second and third period to inflate the predictions from a similar model estimated only on the first period. The resulting predictions for the $\mathrm{A}$ and $\mathrm{B}+$ levels are found to be below the observed ones, which tells us that this type of grade inflation is not sufficient to lead to the observed increases in the proportion of students getting the high grades.

The means of selected explanatory variables for seniors are reported in Table 3 for each of the three time periods of interest. ${ }^{24}$ The first row displays the students' own evaluation of their school ability. It shows that despite having lower grades, boys rate

24. The statistics are computed on observations with no missing variables. This reduces the sample sizes by comparison with Table 2. Complete descriptive statistics for twelfth graders are presented in Table A2 of Fortin, Oreopoulos, and Phipps (2013). Descriptive statistics for eighth graders are available upon request. 

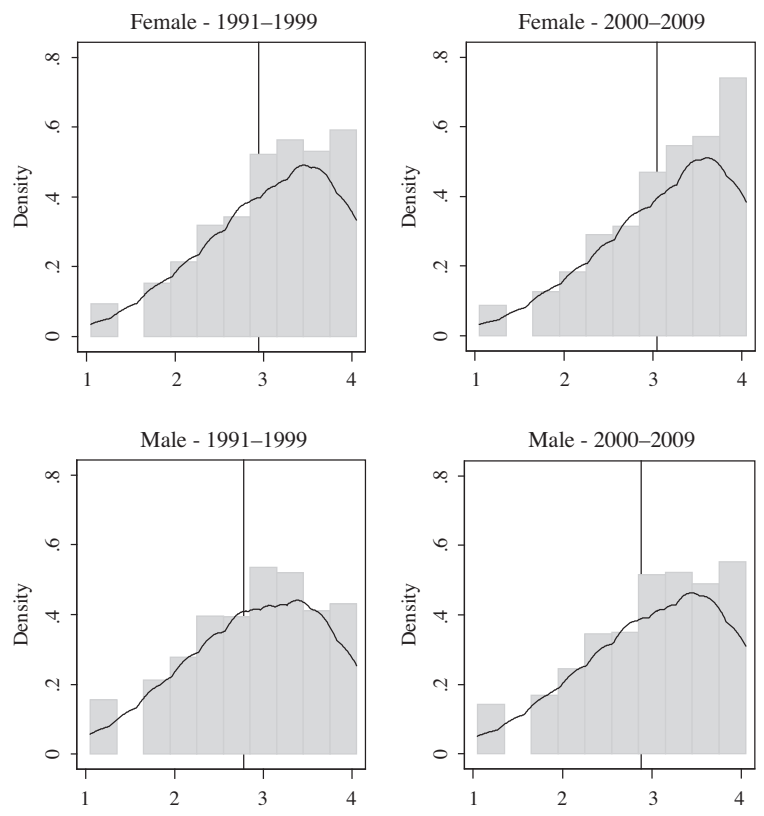

\section{Figure 4 \\ Male and Female Densities of Self-Reported Grades Among Eighth Graders}

Notes: Average grades are indicated by vertical line. Histogram that corresponds to actual data is overlaid with a kernel density.

their own school ability higher than girls. ${ }^{25}$ Similar male overconfidence has been reported among college students by Stinebricker and Stinebricker (2012) who find that college-bound boys are less likely to succeed because of their overall lower performance. ${ }^{26}$

The variables capturing the plans for the future follow. Among twelfth graders, the first question about post-secondary plans asks about expectations: "Core 21: How likely (definitively won't, probably won't, probably will, definitively will) is it that you will do each of the following things after high school? (a) attend a technical or vocational school, (b) serve in the armed forces, (c) graduate from a two-year college, (d) graduate from college (four-year program), (e) attend graduate or professional school after college?" A second question asks about aspirations: "Core 22: Suppose you could do just what you'd like and nothing stood in your way. How many

25. Girls in 1976-88 and boys in 2000-2009 have similar average GPA of 3.0 but the boys' school ability index of 0.664 is significantly greater than the girls' 0.651 .

26. Although grades by topic are not reported in the MTF, numerous studies (especially those using the National Education Longitudinal Study) show that boys continue to maintain an advantage in math test scores (but not in math grades), especially at the high end of the distribution. The boys' overconfidence may be built on these scores. 
Table 3

Means of Selected Core Variables by Gender-Twelfth Graders

\begin{tabular}{|c|c|c|c|c|c|c|c|c|c|}
\hline \multirow[b]{2}{*}{ Core Variables } & \multicolumn{3}{|c|}{$1976-88$} & \multicolumn{3}{|c|}{ 1989-99 } & \multicolumn{3}{|c|}{ 2000-2009 } \\
\hline & Boys & Girls & & Boys & Girls & & Boys & Girls & \\
\hline $\begin{array}{l}\text { Subjective school } \\
\text { ability index }\end{array}$ & 0.652 & 0.651 & & 0.658 & 0.654 & & 0.664 & 0.658 & * \\
\hline $\begin{array}{l}\text { Educational expectations: } \\
\text { Index of likeliness } \\
\text { to attend }^{\mathrm{a}}\end{array}$ & & & & & & & & & \\
\hline Army & 0.281 & 0.102 & $*$ & 0.215 & 0.078 & $*$ & 0.202 & 0.079 & * \\
\hline Vocational & 0.319 & 0.264 & $*$ & 0.268 & 0.210 & $*$ & 0.274 & 0.208 & * \\
\hline Two-year college & 0.338 & 0.364 & $*$ & 0.362 & 0.370 & $*$ & 0.383 & 0.386 & \\
\hline Four-year college & 0.584 & 0.585 & & 0.702 & 0.758 & $*$ & 0.737 & 0.816 & $*$ \\
\hline Graduate or professional & 0.389 & 0.385 & $*$ & 0.471 & 0.530 & $*$ & 0.490 & 0.571 & $*$ \\
\hline $\begin{array}{l}\text { Education aspirations: } \\
\text { Want to attend dummy }\end{array}$ & & & & & & & & & \\
\hline Army & 0.203 & 0.092 & $*$ & 0.177 & 0.079 & $*$ & 0.179 & 0.078 & * \\
\hline Vocational & 0.284 & 0.219 & $*$ & 0.207 & 0.141 & $*$ & 0.203 & 0.124 & $*$ \\
\hline Two-year college & 0.206 & 0.293 & $*$ & 0.214 & 0.256 & $*$ & 0.240 & 0.266 & $*$ \\
\hline Four-year college & 0.635 & 0.650 & $*$ & 0.744 & 0.810 & $*$ & 0.773 & 0.850 & $*$ \\
\hline Graduate or professional & 0.416 & 0.432 & $*$ & 0.529 & 0.613 & $*$ & 0.519 & 0.625 & $*$ \\
\hline High school program: & & & & & & & & & \\
\hline Academic & 0.487 & 0.514 & $*$ & 0.550 & 0.611 & $*$ & 0.518 & 0.589 & $*$ \\
\hline General & 0.300 & 0.307 & $*$ & 0.283 & 0.272 & $*$ & 0.328 & 0.298 & $*$ \\
\hline Vocational & 0.155 & 0.120 & $*$ & 0.107 & 0.068 & $*$ & 0.081 & 0.049 & $*$ \\
\hline Other & 0.059 & 0.060 & & 0.059 & 0.049 & $*$ & 0.073 & 0.065 & $*$ \\
\hline $\begin{array}{l}\text { Cigarette smoking: } \\
\text { less than one-half pack }\end{array}$ & 0.212 & 0.260 & $*$ & 0.258 & 0.260 & & 0.217 & 0.201 & $*$ \\
\hline $\begin{array}{l}\text { Alcohol binging last two } \\
\text { weeks: two to } \\
\text { nine times }\end{array}$ & 0.307 & 0.167 & $*$ & 0.231 & 0.127 & $*$ & 0.197 & 0.121 & * \\
\hline Father not same household & 0.169 & 0.185 & $*$ & 0.201 & 0.228 & $*$ & 0.207 & 0.244 & $*$ \\
\hline Mother working all the time & 0.201 & 0.234 & $*$ & 0.353 & 0.398 & $*$ & 0.462 & 0.495 & $*$ \\
\hline Father: some high school & 0.145 & 0.154 & $*$ & 0.101 & 0.110 & $*$ & 0.098 & 0.108 & $*$ \\
\hline Father: completed college & 0.190 & 0.176 & $*$ & 0.230 & 0.214 & $*$ & 0.253 & 0.225 & $*$ \\
\hline Mother: some high school & 0.126 & 0.149 & $*$ & 0.082 & 0.101 & $*$ & 0.071 & 0.082 & $*$ \\
\hline Mother: completed college & 0.164 & 0.146 & $*$ & 0.234 & 0.211 & $*$ & 0.290 & 0.257 & * \\
\hline Works over school year & 0.848 & 0.798 & $*$ & 0.801 & 0.792 & $*$ & 0.755 & 0.756 & \\
\hline Number of observations & 74,230 & 79,942 & & 60,469 & 66,875 & & 50,549 & 57,202 & \\
\hline
\end{tabular}

Notes: Asterisk indicates statistically significant gender difference at the 5 percent level. Means of other variables and other categories are reported in Fortin, Oreopoulos, and Phipps (2013).

aThe four categories of likeliness are: definitively won't, probably won't, probably will, definitively will. 
of the following things would you WANT to do?" with the five options above being supplemented by "none of the above." The expectations question raises issues of endogeneity with respect to GPA. Some high-ability students may have low expectations of graduating from a four-year college because of their low GPA, rather than the other way around. The aspirations question attempts to circumvent that problem with the preamble if "nothing stood in your way." Controlling for subjective school ability (Core 16 above) and aspirations (Core 22) is an attempt to alleviate concerns about cognitive dissonance. Among eighth graders, the issue of endogeneity of educational expectations is presumably less severe as there is more time to adjust one's level of effort. ${ }^{27}$ For these students, we control for two retrospective measures of school ability (grade retention and whether school was often hard) as well as school misbehavior. ${ }^{28}$

Table 3 shows that in the 1980s, although seniors of both genders had similar expectations about graduating from college and attending graduate school, girls already had higher aspirations (close to two percentage points) than boys. By the 2000s, the expectations index for both college and graduate school was eight percentage points higher for girls than boys. ${ }^{29}$ Gender differences in aspirations for college and graduate school are respectively eight percentage points and eleven percentage points higher in favor of girls. Finally, 6 percent of boys versus 3 percent of girls have declared no post-secondary aspirations. Next, the types of high school programs show that the gap in favor of girls in the proportion of seniors enrolled in an academic program has grown. While about 3 percent more girls than boys were enrolled in an academic program in the 1980 s, that proportion increased to 7 percent in the 2000 s. Among eighth graders, already 4 percent more girls than boys report being enrolled in a college preparatory program although a large proportion of students ( 43 percent of both boys and girls) have not made clear choices yet.

Table 3 also presents some selected demographic characteristics. The high alcohol binging category shows that boys are still more likely than girls to report these risky behaviors. Girls tend to live in families that might appear less likely to foster high academic achievement. Four percent more girls than boys report not living in the same household as their father, 3 percent more girls than boys report that their mother works all the time, and about 3 percent more boys than girls report that their father or mother has completed college. ${ }^{30}$ The final row shows that the gender gap in paid work participation has closed over time, although boys continue to work longer hours and get higher pay.

27. Among eighth graders, only the expectations questions are asked.

28. More precisely, responses to the grade retention question "Have you ever had to repeat a grade in school?" are available as a binary variable. The responses to the two questions: "Now thinking back over the past year in school, how often did you ... find the school work too hard to understand?" “... get sent to the office, or have to stay after school, because you misbehaved?" were coded on a five point scale.

29. Comparing seniors in 1972 from the NLS72, in 1980 from the H\&B, in 1992 from the NELS88, and in 2004 from the ELS2002, Ingels, Dalton, and LoGerfo (2008) also find that in 2004 more girls than boys expected to pursue graduate studies, whereas it was the opposite in 1972.

30. We note that the gender gaps in family characteristics are similar in the sample without Blacks. 


\section{Empirical Specification and Reweighted Decomposition Methodology}

Our empirical specification is based on a behavioral threshold model of academic performance where educational goals, fashioned in elementary school and likely influenced by parental desires, play a prominent role in determining, given a level of aptitude, an individual's choice of optimal GPA. ${ }^{31}$ This follows an emerging consensus in the psychology literature that students form reliable perceptions of their academic competency around fifth grade (Herbert and Stipek 2005) and already can form some expectations about going to college. ${ }^{32}$ Indeed, decisions to enroll in a college preparatory high school program, to move to a neighborhood with a better high school, and to apply to a magnet school have to be made early in a student's life. Under the assumption that effort is costly, the student's optimal choice of GPA will be the minimum of the range that opens the door to the education level needed to fulfill her/his vocational goals. Students motivated toward professional or medical careers will come to understand they need to aim for As. Those thinking about white-collar occupations, such as financial analyst, will need a bachelor's degree and can aim for Bs; those expecting jobs that require fewer credentials may instead aim for Cs.

The changes over time in the shape in the distribution of GPA levels from a bell shape to a staircase shape (shown in Figures 3 and 4) are consistent with a threshold model in the presence of changes in career expectations, especially for girls. The less pronounced change in shape among boys would be consistent with more convex costs of effort, possibly associated with higher psychic or social costs of being seen as working hard. ${ }^{33}$ This type of threshold model helps rationalize the relative underperformance of boys as the consequence of career choices that require lower levels of educational attainment. We do not exclude the possibility that some students revise their plans, but because we do not have access to the MTF longitudinal data, we cannot explore this avenue. ${ }^{34}$ Another attractive strategy could have used changes over time in local labor market opportunities by gender as an instrument to predict exogenous variations in gender specific student expectations. Here again, we lack information about geographical location to exploit cross-sectional changes in labor market or other exogenous changes.

In this study of gender gaps in academic achievement, we simply seek to identify how student characteristics map into the distribution of GPAs differently by gender. We are primarily interested in how changes over time in these determinants help account for changes over time in gender differentials in academic achievement. For each of the three time periods, we estimate the following academic achievement equation,

$$
\text { (1) } \operatorname{Prob}\left[G_{i}=c\right]=h_{g}^{c}\left(S_{i}, A_{i}, L_{i} ; X_{i}, X_{i}^{p}\right), \quad c=1, \ldots, 9 \text {, }
$$

31. The underlying model is exposited in Appendix B of Fortin, Oreopoulos, and Phipps (2013).

32. This is consistent with the high school tracking taking place in many European countries around the ages of ten and 11 (for example, Dustmann 2004).

33. Bishop (2006) argues that there are different studying and homework cultures by gender, something like "smart boys get high marks without showing effort" or "it is not cool for boys to work hard to get top grades." 34. Not having access to the longitudinal MTF data, we cannot address directly the issue of expectations formation by contrast with Stange (2008), Zafar (2011) and Jacob and Wilder (2012). Jacob and Wilder, using data from the NELS88, report that 25 percent of high school students update their educational expectations from Grades 10 to 12 . 
where $G_{i}$ is the student's GPA, $S_{i}$ denotes the student's educational goals, and $A_{i}$ denotes the student' academic aptitude. We combine the high school program, the schooling expectations, and aspirations to measure $S_{i}$. The student's school aptitude, $A_{i}$, is proxied using the subjective measure of school ability (introduced in Section II) available for twelfth grade students. ${ }^{35}$ For eighth grade students, we measure aptitude by how often he or she found school "too hard" in the last year, in addition to a measure of past grade retention. We include an indirect measure of effort, following the tradition in labor economics of deriving nonmarket time, here study time, as the difference between total time $(T)$ and labor market time $\left(L_{i}\right): E_{i}=T-L_{i}$. To explore the impact of noncognitive skills, we include measures of cigarette smoking and alcohol binging, which may relate to time impatience, and a measure of school misbehavior for eighth graders. Exogenous characteristics of student $X_{i}$ are included, including race and living in an SMSA, as well as an extended set of family characteristics, $X_{i}^{p}$, thought to be predetermined variables. ${ }^{36}$

We estimate a different linear probability model by gender for each level of GPA, which carries some advantages and disadvantages. The advantages of using a linear probability model are that we do not have to rely on the assumptions of normality of residuals. By comparison with an ordered probit model, this model allows the educational responses to be different by level of GPA. Given that the detailed decomposition of the gender differentials requires linear educational responses, this estimation procedure gives us coefficients that can readily be used. ${ }^{37}$

We use an extension (Fortin, Lemieux, and Firpo 2011) to the standard OaxacaBlinder $(\mathrm{OB})$ decomposition that allows us to analyze the impact of gender differences in the educational response functions. We now give a short summary of the formulas behind this modified decomposition. With the standard OB decomposition, the researcher seeks to determine what portion of the gender gap in grades is attributable or "explained" by differences in the characteristics of boys and girls and what portion remains "unexplained." Here, owing to reweighting, we can argue that the "unexplained" part corresponds to gender differences in the structural function $h_{g}^{c}\left(S_{i}, A_{i}, L_{i} ; X_{i}, X_{i}^{p}\right)$ of Equation 1. In the detailed decomposition, we can apportion parts of the aggregate decomposition to particular explanatory factors and responses to determine their relative importance.

Assuming that grades $(G)$ can be modeled as a linear (in the parameters) function of characteristics $(X)$ that is different for girls $(F=1)$ and boys $(F=0)$.

$$
\mathbb{E}(G \mid X, F=1)=\mathbb{E}(X \mid F=1) \beta_{1} \text { and } \mathbb{E}(G \mid X, F=0)=\mathbb{E}(X \mid F=0) \beta_{0},
$$

under the zero conditional mean assumption, $\mathbb{E}(\varepsilon \mid X, F)=0$. The classic OB counterfactual, $\mathbb{E}\left(G^{O B}\right)=\mathbb{E}(X \mid F=1) \beta_{0}$, asks "What would boys' grades be if they had the same characteristics as girls?" using the coefficients estimated on the sample of

35. Educational aspirations and subjective school ability measures are available only for the twelfth graders. Clearly, lagged measures would have been preferred.

36. These family environment characteristics include living in the same household as the father, the mother, and siblings (separate questions), the number of siblings, whether the mother had a paid job while growing up (not at all, some of the time, most of the time, all the time), and the level of education (six levels) of the father and of the mother.

37. Among the disadvantages is the fact that the predicted probabilities are not bounded between 0 and 1 . In practice, we will find some underpredictions $(<0)$ but the predicted probabilities over GPA levels sum to 1. 
boys. As shown in Fortin, Lemieux, and Firpo (2011), with reweighting we can construct a counterfactual that more precisely isolates the educational responses. This counterfactual uses the coefficients estimated using the grades outcomes of boys but the characteristics of the sample of boys reweighted to be like girls.

More precisely, we reweight the sample of boys so that the distribution of their characteristics $(X)$ is similar to that of girls using the following reweighting function

$$
\begin{aligned}
\Psi(X) & =[(\operatorname{Prob}(X \mid F=1)) /(\operatorname{Prob}(X \mid F=0))] \\
& =[(\operatorname{Prob}(F=1 \mid X)) /(\operatorname{Prob}(F=0 \mid X))] \cdot[\operatorname{Prob}(F=0) / \operatorname{Prob}(F=1)] .{ }^{38}
\end{aligned}
$$

The counterfactual coefficients $\beta_{o}^{1}$ are estimated on the sample of boys reweighted to look like girls' $\left\{X_{0}, \Psi\left(X_{0}\right)\right\}$. The difference $\left(\beta_{1}-\beta_{o}^{1}\right)$ reflects the true gender gap in educational responses, and the counterfactual means are computed as: $\bar{X}_{0}^{1}=\Sigma\{i: F=0\} \Psi\left(X_{i}\right) \cdot X_{i}$. The reweighted decomposition uses the predicted grades, $\left(X_{0} \mid F=1\right) \beta_{o}^{1}$, from the reweighted sample as counterfactuals,

$$
\begin{aligned}
& \Delta_{O, R}^{\mu}=\mathbb{E}(X \mid F=1) \beta_{1}-\mathbb{E}\left(X_{0} \mid F=1\right) \beta_{o}^{1}+\mathbb{E}\left(X_{0} \mid F=1\right) \beta_{o}^{1}-\mathbb{E}(X \mid F=0) \beta_{0} \\
& =\quad \Delta_{E, R}^{\mu} \quad+\quad \Delta_{X, R}^{\mu}
\end{aligned}
$$

to obtain an aggregate decomposition as the sum of an educational response effect, $\Delta_{E, R}^{\mu}$, and a composition effect, $\Delta_{X, R}^{\mu}$. Inasmuch as grade dummies can be averaged out, this decomposition relies on the additional assumptions of common support and ignorability ( $F \perp \varepsilon \mid X$ ); that is conditioning of observables, unobservables are assumed to be the same across gender. ${ }^{39}$

Each term of the reweighted decomposition can be further broken down into the "pure" effect and a residual term. The composition effect, $\Delta_{X, R}^{\mu}$, is written as the sum of a pure composition effect, $\Delta_{X, p}^{\mu}$, and a specification error, $\Delta_{X, e}^{\mu}$,

$$
\begin{aligned}
\Delta_{X, R}^{\mu} & =\mathbb{E}\left(X_{0} \mid F=1\right) \beta_{o}^{1}-\mathbb{E}(X \mid F=0) \beta_{0}+\mathbb{E}\left(X_{0} \mid F=1\right) \beta_{0}-\mathbb{E}\left(X_{0} \mid F=1\right) \beta_{0} \\
& =\left[\mathbb{E}\left(X_{0} \mid F=1\right)-\mathbb{E}(X \mid F=0)\right] \beta_{0}+\mathbb{E}\left(X_{0} \mid F=1\right)\left(\beta_{o}^{1}-\beta_{0}\right) \\
& = \\
\Delta_{X, p}^{\mu} & +\quad \Delta_{X, e^{*}}^{\mu}
\end{aligned}
$$

Similarly, the educational response term, $\Delta_{E, R}^{\mu}$, can be written as the sum of a pure response effect $\Delta_{E, p}^{\mu}$ plus a reweighting error $\Delta_{E, e}^{\mu}$,

$$
\begin{aligned}
\Delta_{E, R}^{\mu} & \left.=\mathbb{E}(X \mid F=1) \beta_{1}-\mathbb{E}\left(X_{0} \mid F=1\right)\right] \beta_{o}^{1}-\mathbb{E}(X \mid F=1) \beta_{o}^{1}+\mathbb{E}(X \mid F=1) \beta_{o}^{1} \\
& =\mathbb{E}(X \mid F=1)\left(\beta_{1}-\beta_{o}^{1}\right)+\left[\mathbb{E}(X \mid F=1)-\mathbb{E}\left(X_{0} \mid F=1\right)\right] \beta_{o}^{1} \\
& =\quad \Delta_{E, p}^{\mu} \quad+\quad \Delta_{E, e^{.}}^{\mu}
\end{aligned}
$$

38. The second equation makes use of Bayes' Law to allow the computation $\Psi(X)$ in the case of continuous $X$ variables. See DiNardo, Fortin, and Lemieux (1996) for details.

39. The ignorability assumption is a strong assumption that can never be tested directly. We contend that given our large set of noncognitive skills, it is more likely to hold than in other analyses that lack these variables. 
The specification error $\Delta_{X, e}^{\mu}=\mathbb{E}\left(X_{0} \mid F=1\right)\left(\beta_{o}^{1}-\beta_{0}\right)$ corresponds to the difference in the composition effects estimated by reweighting and by using simple regressions, where $\mathbb{E}\left(X_{0} \mid F=1\right)$ is the mean of the reweighted sample; it captures the departures from nonlinearity. The reweighting error $\Delta_{E, e}^{\mu}=\left[\mathbb{E}(X \mid F=1)-\mathbb{E}\left(X_{0} \mid F=1\right)\right] \beta_{o}^{1}$ goes to zero in a large sample.

Because of the linearity of these expressions, the detailed decomposition or the apportionment of the composition and educational response effects to each explanatory variable is straightforward. In practice, this detailed reweighted decomposition can be obtained by running two decompositions: OB(1) with the sample of girls $(F=1)$ and the reweighted sample of boys looking like girls to get the pure educational response effect; and $\mathrm{OB}(2)$ with the sample of boys $(F=0)$ and the reweighted sample of boys looking like girls to get the pure composition effect.

\section{Empirical Results}

Before going on to the decomposition results, it is useful to show which of our explanatory variables are more significant in explaining a cross-section in grade outcomes and how these relationships differ by gender. To conserve space, we report selected estimated coefficients only for seniors in the 2000s and only for the two GPA levels where the gender achievement gaps are largest, that is, for the A and C+ grades, and only for girls and boys, and not for the reweighted sample of boys, which are used in the decompositions..$^{40}$

\section{A. Determinants of Top and Below Average GPA}

Tables $4 \mathrm{a}$ and $4 \mathrm{~b}$ report the estimated coefficients of the explanatory variables listed in Table 3 along with $t$-statistics. In Table $4 \mathrm{a}$, the dependent variable is equal to 100 if the student gets an A and 0 otherwise so that the coefficients indicate the added probability of getting an A associated with the explanatory variables. In Table $4 \mathrm{~b}$, we estimate the covariates of getting exactly a $\mathrm{C}+$. Specification 1 includes educational expectations under the assumption that students take their abilities and other limitations into account when formulating their expectations. Specification 2 explores the consequences of this assumption by explicitly controlling for subjective school ability and for educational aspirations formed without possible limitations resulting from ability or other constraints. ${ }^{41}$ When we control for student ability and student aspirations, the explanatory power of expectations is reduced; this is indicative of potential endogeneity biases that we can control for only to some extent. Yet educational expectations remain among the most significant explanatory variables. In Table 4a, wanting and expecting to attend graduate school, especially among boys, is associated with a higher probability, in the four to fourteen percentage point range of getting an A. Conversely, expecting to go to a two-year college shows a negative association, in the

40. The coefficients estimated on the reweighted sample are available upon request; they are generally close to the ones estimated on the sample of boys.

41. In Fortin, Oreoupoulos, and Phipps (2013), we also report the estimates from Specification 3 (Table A3), which excludes expectations altogether, leaving the type of high school program to capture plans for the future. 
-7 to -11 percentage point range with getting an A. Expecting to go to a four-year college is so widespread that it has little explanatory power. In Table $4 \mathrm{~b}$, consistent with our threshold model, expecting to go to a two-year college is associated with a higher probability, in the two to six percentage point range of getting a $\mathrm{C}+$, again especially for boys. ${ }^{42}$ The types of high school program, thought to be part of a student's plans for the future, show similarly strong associations with these GPA levels and significant differences across genders. Girls in academic high school programs are more likely to get an $\mathrm{A}$ and less likely to get a $\mathrm{C}+$ than boys.

As in Balsaa, Guiliano, and French (2011), alcohol binging is associated with a significantly lower probability of getting an $\mathrm{A}$, about -4 percentage points, and a higher probability of getting a $\mathrm{C}+$, about one to four percentage points. Similar effects are found for smoking variables, in the -3 to -6 percentage point range for getting an $\mathrm{A}$ and the plus two percentage point range for a $\mathrm{C}+$. We view these correlations as symptomatic of time impatience or caring less about the future. Focusing on family background variables, we find that controlling for school ability (going from Specification 1 to 2) substantially reduces the impact of parental education on students' probabilities of getting an $\mathrm{A}$ or a $\mathrm{C}+$ although that association remains significant for girls. ${ }^{43}$ To the extent that parental education is capturing the family socioeconomic status, these results are consistent with past research (for example, Cameron and Heckman 2001, Reynolds and Pemberton 2001), showing that the biggest influence of parental resources on the children's education operates through academic performance. Other important family influences, more impervious to the addition of subjective school ability, are the actual presence of parents in the household. The father not living in the same household and the mother working have significant effects (about -1 to -4 percentage points) on the probability of getting an A, and positive effects on the probability of getting a $\mathrm{C}+$ (about one to two percentage points). Interestingly, the effect of the absent father is somewhat greater for girls and that of the mother working is somewhat greater for boys. Consistent with Buchmann and DiPrete (2006), we find that these effects have increased from the 1980s to the 2000s. In comparison to the above regressors, the effects of the variables related to working during school are generally less significant and show some of the nonlinear patterns found in the literature.

\section{B. Tabular Decomposition Results for Selected GPA Levels}

In Table 5, we present the detailed decompositions for the 2000-2009 time period, for these two GPA levels for seniors and for the eighth grade students. ${ }^{44}$ The results for

42. This interesting new finding would be masked if the dependent variable was getting at least $\mathrm{C}+$. In this case, expecting to go to a four-year college dominates.

43. When the specification excludes educational expectations (see Fortin, Oreopoulos, and Phipps 2013, Specification 3 in Table A3), the coefficients of parental education are larger.

44. The list of variables available for eighth graders is the following: dummies for race (white/non-white), SMSA, ever held back, smoked cigarettes per day (4), alcohol binging within last two weeks (4), sibling not same household, father not same household, mother not same household, mother working (3), father's education (7), mother's education (7), worked during school, average hours of work (6), average earnings (7), type of high school program (4), indexes for school misbehavior last year, school too hard last year, educational expectations (army, vocational, go to college, complete 4-year college). So the main differences with Specification 2 for seniors are the absence of the number of siblings, of the aspirations for post-secondary choices, and the expectations of going to graduate school. 


\section{Table 4a}

Selected Coefficients of LPM on Specific Grades - Twelfth Graders 2000-2009

Dependent variable:

A (93-100 percent) x 100

Specification 1

Specification 2

Explanatory variables

Boys Girls

Subjective school ability

Educational expectations ${ }^{\mathrm{a}}$

\begin{tabular}{|c|c|c|c|c|}
\hline Army & $-2.33 \quad(4.5)$ & $-0.13 \quad(-0.2)$ & $(0.5)$ & 2.34 \\
\hline Vocational & $-3.95 \quad(-7.2)$ & $-3.93(-6.5)$ & $-3.52 \quad(-5.6)$ & $-3.94 \quad(-5.7)$ \\
\hline Two-year college & $-9.95(-22.0)$ & $-11.41(-24.5)$ & $-7.54(-14.5)$ & $-7.04(-12.7)$ \\
\hline Four-year college & $(6.1)$ & (6.4) & $(0.2)$ & 0.57 \\
\hline $\begin{array}{l}\text { Graduate or professional } \\
\text { ducation aspirations }{ }^{\mathrm{b}}\end{array}$ & $13.71 \quad(24.6)$ & $10.40 \quad(18.5)$ & $8.66 \quad(14.1)$ & 4.10 \\
\hline Army & & & $-2.51 \quad(-5.1)$ & $-2.21 \quad(-3.1)$ \\
\hline Vocational & & & $-0.14 \quad(-0.3)$ & 1.15 \\
\hline Two-year college & & & $(0.5)$ & $-0.20 \quad(-0.4)$ \\
\hline Four-year college & & & $-1.74 \quad(-4.0)$ & $-1.32(-2.5)$ \\
\hline $\begin{array}{l}\text { Graduate or professional } \\
\text { ligh school program }\end{array}$ & & & $(4.3)$ & 2.07 \\
\hline Academic & $(9.4)$ & $9.09 \quad(13.0)$ & $(2.1)$ & 2.01 \\
\hline General & $-1.43 \quad(-2.3)$ & $-0.29 \quad(-0.4)$ & $-2.83 \quad(-4.7)$ & $-1.89 \quad(-2.8)$ \\
\hline Vocational & $2.47 \quad(3.1)$ & $(9.4)$ & $-0.25 \quad(-0.3)$ & 1.33 \\
\hline $\begin{array}{l}\text { igarette smoking: } \\
\text { less than one-half pack }\end{array}$ & $-4.93(-12.4)$ & $-7.79(-17.7)$ & $-3.64 \quad(-9.4)$ & $-6.11(-14.5)$ \\
\hline $\begin{array}{l}\text { lcohol binging last } \\
\text { two weeks: two } \\
\text { to nine times }\end{array}$ & $-4.98(-12.0)$ & $-5.25 \quad(-9.8)$ & $-4.66(-11.6)$ & $-4.01 \quad(-7.8)$ \\
\hline ather not same household & $-1.23(-3.1)$ & $-2.32 \quad(-5.7)$ & $-0.87 \quad(-2.2)$ & $-1.89 \quad(-4.9)$ \\
\hline Iother working: all the time & $-3.86 \quad(-8.3)$ & $-4.76 \quad(-9.5)$ & $-3.51 \quad(-7.8)$ & $-3.84 \quad(-8.0)$ \\
\hline ather: completed college & $(2.0)$ & $2.88 \quad(6.0)$ & $(0.3)$ & 1.71 \\
\hline Iother: completed college & (3.3) & (6.3) & (1.6) & 1.45 \\
\hline Vorks over school year & $-3.09 \quad(-2.6)$ & $(0.2)$ & $-2.21 \quad(-1.9)$ & 2.14 \\
\hline onstant & $25.24 \quad(28.4)$ & $28.76 \quad(29.6)$ & $-1.31 \quad(-1.3)$ & $-13.36(-11.4)$ \\
\hline -squared & 0.12 & 0.13 & 0.17 & 0.20 \\
\hline Tumber of observations & 49,328 & 56,156 & 49,328 & 56,156 \\
\hline
\end{tabular}

Notes: Dependent variable is set to 100 if the student has a GPA of 4 , and to 0 otherwise. $T$-statistics are in parentheses. The base group for Alcohol binging and Cigarette smoking is none, Mother working is not working, Father's and Mother's education is high school, for High school program is other. The coefficients of the other variables and categories included in the regression are reported in Fortin, Oreopoulos, and Phipps (2013).

'Index of educational expectations constructed from the four categories: definitively won't, probably won't, probably will, definitively will.

${ }^{b}$ Educational aspirations measured with binary variable: want to attend. 


\section{Table 4b}

Selected Coefficients of LPM on Specific Grades - Twelfth Graders 2000-2009

Dependent variable:

$\mathrm{C}+(77-79$ percent $) \times 100$

Specification 1

Specification 2

Explanatory variables

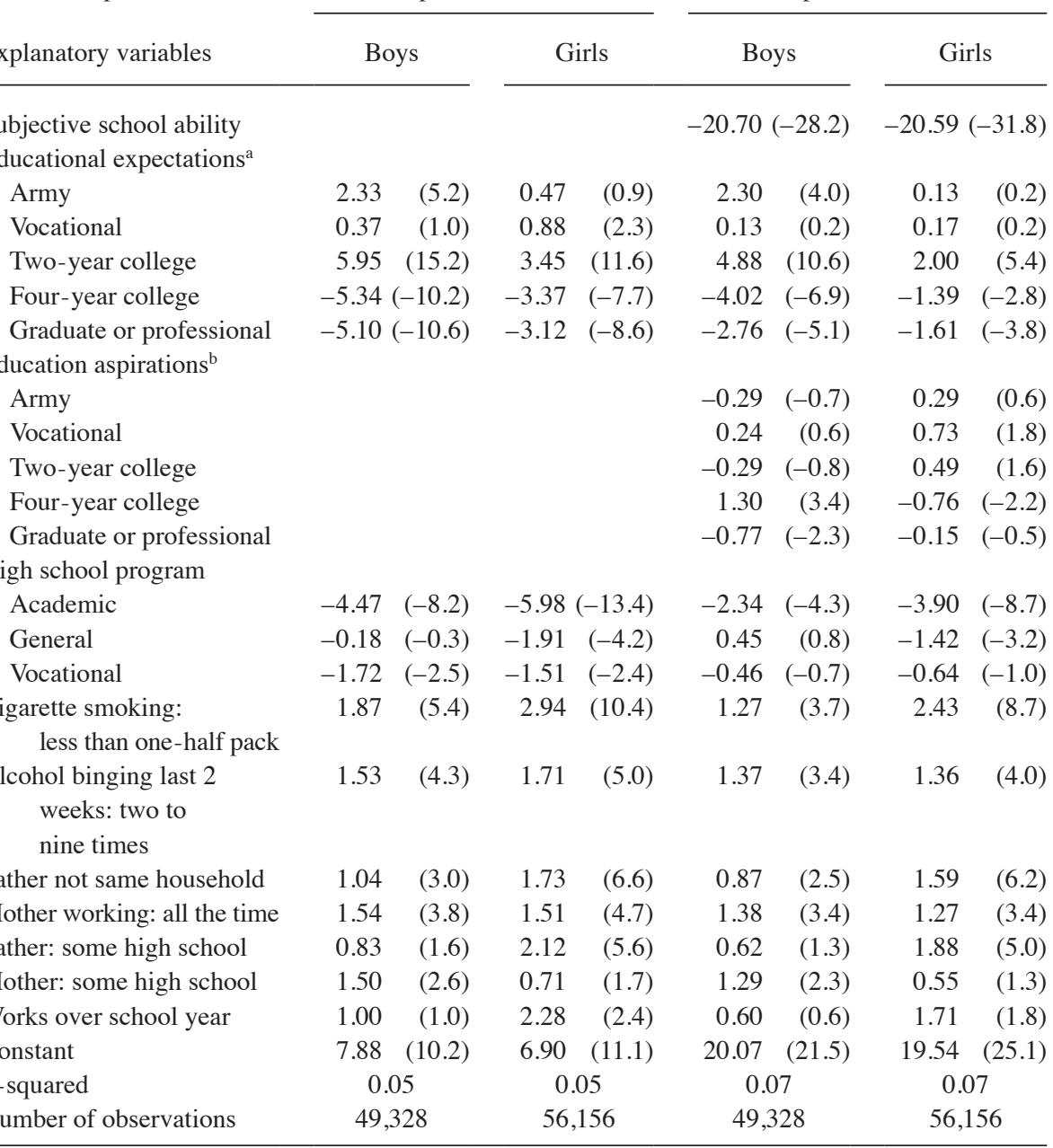

Subjective school ability

Educational expectations ${ }^{\mathrm{a}}$

Notes: Dependent variable is set to 100 if the student has a GPA of 2.3 , and to 0 otherwise. $T$-statistics are in parentheses. The base group for Alcohol binging and Cigarette smoking is none, Mother working is not working, Father's and Mother's education is high school, for High school program is other. The coefficients of the other variables and categories included in the regression are reported in Fortin, Oreopoulos, and Phipps (2013).

'Index of educational expectations constructed from the four categories: definitively won't, probably won't, probably will, definitively will.

${ }^{b}$ Educational aspirations measured with binary variable: want to attend. 


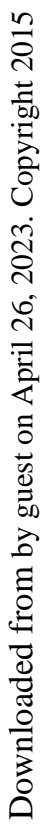

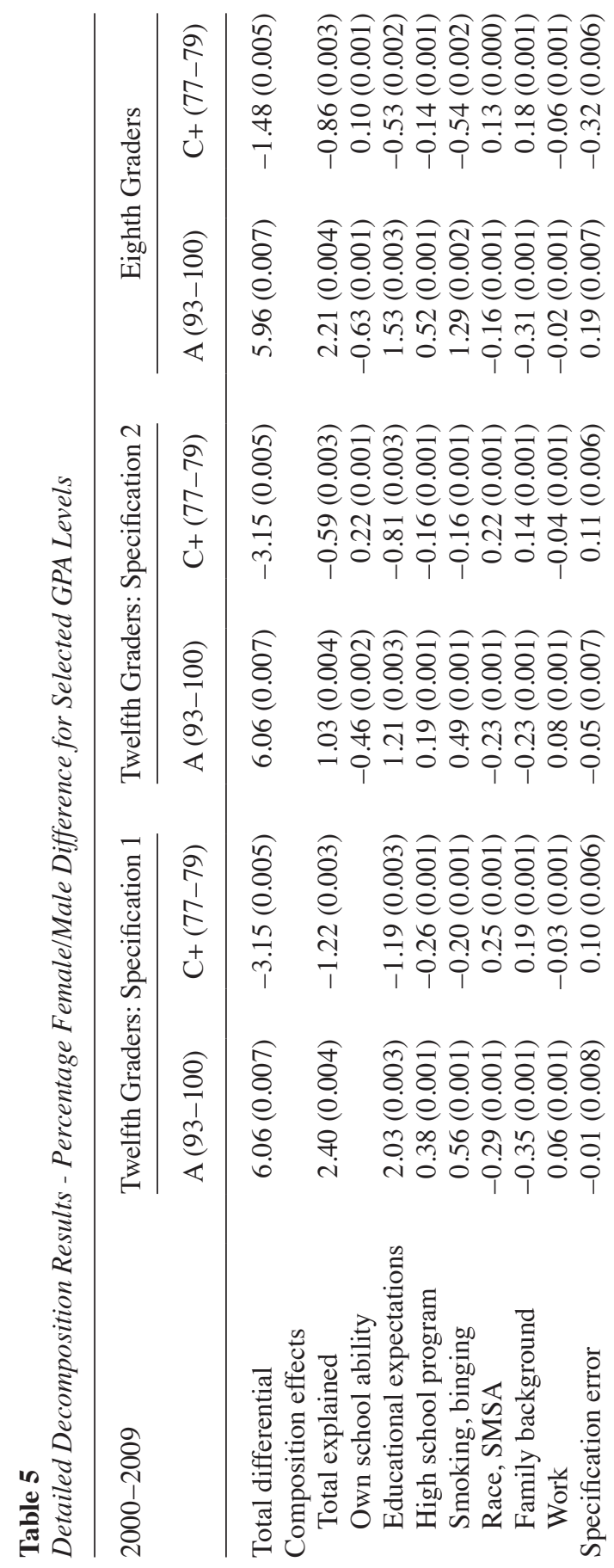




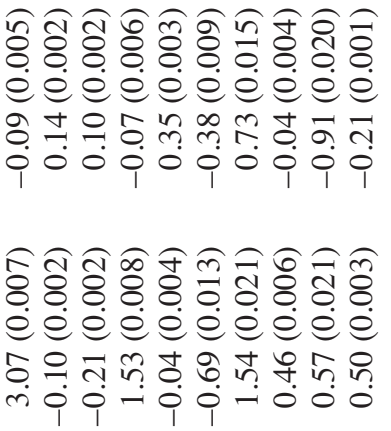

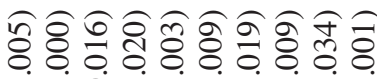
é巳é巳é巳é巳é

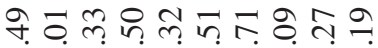

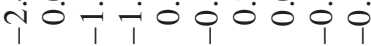

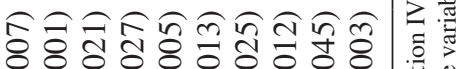

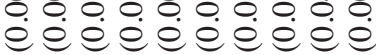

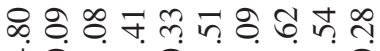
+0

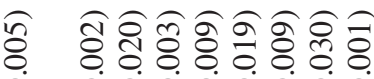
- ejeejeé

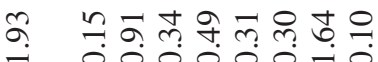
1

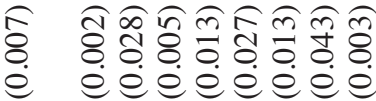

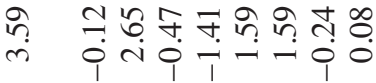

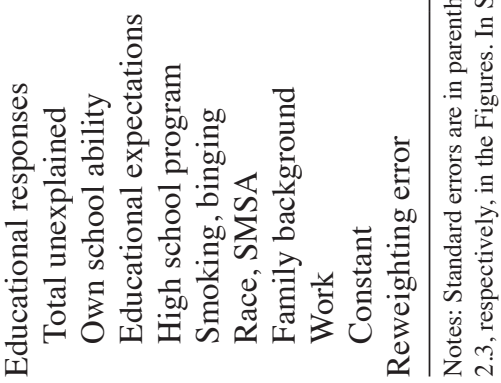


the earlier periods are reported in Fortin, Oreopoulos, and Phipps (2013) Appendix Tables A4 and A5. With regard to change over time in the aggregate decomposition for twelfth graders, most notable is the fact that the portions attributable to composition effects - the "explained" part - increased over the three time periods, especially at the top of the grade distribution. ${ }^{45}$ Averaging over all GPA levels, the "explained" part grew from a mere 10 percent of the total gender differential in the 1980 s to 32 percent in the 1990s and to 37 percent in the 2000s. As we argue below, the larger increase from the 1980 s to 1990 s can be attributed to larger increases in the gender differential in educational expectations during that period.

We begin by discussing the composition effects in the upper panel of Table 5 . Because the female/male difference in school aptitude is negative, the effects of subjective school ability for seniors, and of the two retrospective measures of aptitude for eighth graders, go in the wrong direction: Their coefficients are positive for top grades and negative for mediocre grades. This reduces part of the gender differentials, negative for top grades and positive for mediocre grades, accounted for by the explanatory variables. For example, in Table 5, see the reduction in "Total Explained" going from Specification 1 to Specification $2 .{ }^{46}$ We also note that race, living in a standard metropolitan statistical area (SMSA), and family background variables are other sets of "contrarian" or "swimming upstream" variables: These variables work to the advantage of boys (because there are more Black girls, more girls with absent father, etc.) and reduce the percentage of girls with top grades and of boys with mediocre grades. That is, if girls were as confident as boys about their school ability, if they lived in similar families, if there were as few Black girls living in SMSAs as boys, the girls' grades would be even higher. In the $2000 \mathrm{~s}$, there would be from 0.6 to 0.9 percent more girls than boys earning As. Although minor, it is still interesting to find that some high-achieving girls are "swimming upstream."

Our major result is that educational expectations are the most important factor accounting for gender differentials in academic achievement. Table 5 shows that for seniors with A grades, gender differences in expectations account for 2.03 out of 2.44 percentage points of the "explained" by gender differences in characteristics (in Specification 1) in the 2000s. This is up from 1.13 in the 1990 s and from 0.23 in the $1980 \mathrm{~s} .{ }^{47}$ For the $\mathrm{C}+$ grades, the numbers are -1.19 out of -1.22 percentage points of the "explained" in the 2000 s, up from -0.66 in the 1990 s and from -0.08 in the 1980 s. As noted above, controlling for subjective school ability (Specification 2) reduces the absolute magnitude of the gender differentials accounted for by expectations but not the portion explained. From the 1980 s to the 2000 s, the role of educational expectations has gone from being virtually negligible to accounting for almost all gender differentials in these GPA levels.

For eighth graders, we find similarly impressive results in the accounting power of expectations: For the A grades, the part explained by expectations is 1.53 out of

45. As illustrated in Figure 5 of Fortin, Oreopoulos, and Phipps (2013).

46. This effect is similar to the gender differences in educational attainment on the gender pay gap. In recent years, gender differences in education reduce the explained part of the gender pay gap. In the 2000s, the Total Explained corresponds to more than 40 percent of the gender achievement gap in Specification 1 but only 17 percent in Specification 2.

47. Comparing Table 5 and Tables A4 and A5 of Fortin, Oreopoulos, and Phipps (2013) shows that these effects increased over time. 
2.21 "Total Explained" in the 2000s, up from 1.07 in the 1990s. Overall, these results convey the same message as the one suggested by Table 2: That here, even after controlling for a host of other factors, gender differences in educational expectations (and changes therein) account for the largest share (and the most salient changes over time) in the gender differentials.

Noncognitive skills are another set of variables that has consistent explanatory power across all specifications for why girls have higher grades than boys. They are measured by smoking and alcohol binging among seniors and with the addition of school misbehavior among eighth graders. For top grades, they account for 0.49 to 0.56 , and for 1.26 of the gender gap, among seniors and eighth graders, respectively. For mediocre grades, the numbers are large only for eighth graders. Among eighth graders, expectations and noncognitive skills account for similarly large shares of the gender gap for top and mediocre grades. We find that gender differences in noncognitive skills are the second most important factor to account for "explained" gender differences in academic achievement. ${ }^{48}$

Finally, we consider the contribution of changes in gender differences in educational responses presented in the bottom panel of Table 5, noting that the interpretation of these differences crucially depends on the omitted category in each case. The most important difference is linked to the type of high school program attended, where the omitted category is "other (not specified) high school." As we saw in previous tables, not only are girls increasingly attending college preparatory high school but they are benefiting more (in terms of grades) from it than boys. This differential educational response adds to the total effect of "plans for the future" factors in accounting for gender differences in academic achievement.

The effects of gender differences in educational responses associated with family background is more difficult to interpret because departures from the omitted category (families with father present, mother present, one sibling, mother not working, both parents with high school education) are a more complex affair and the results are sensitive to which number of siblings is the omitted category (especially in the 1990s). ${ }^{49}$ Nevertheless, they indicate that family background generally bolsters the response of high-achieving girls by comparison with boys. A similar effect seems to apply to "work during school," where the omitted categories are not working, zero hours of work, and zero wages. ${ }^{50}$ Working during school seems to act as a complement rather than a distraction for high-achieving girls.

\section{Graphical Detailed Decomposition Results for all GPA Levels and Time Periods}

Figure 5 for twelfth graders and Figure 6 for eighth graders display the results of the detailed decomposition for each GPA level for each category of factors. The lines trace the magnitude of the gender gap: Positive numbers indicate a larger value for females, negative numbers indicate a larger value for males. The numbers behind the

48. However, we find some evidence that these effects are decreasing over time, at least for twelfth graders. 49. Such sensitivity is not surprising, given that even using an instrumental variable strategy that exploits exogenous variation in family size, Conley and Glauber (2006) find a strong effect of sibship size on second-born boys' grade retention but no effect on first-born boys.

50. Note that working during school is the factor that has the least economic significance in the composition effects. 
A. Plans for the Future

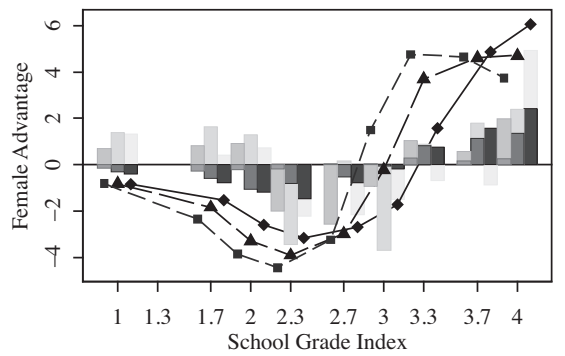

C. Family Background

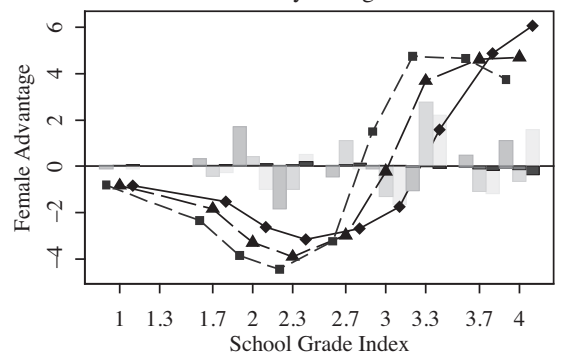

B. Student Attributes

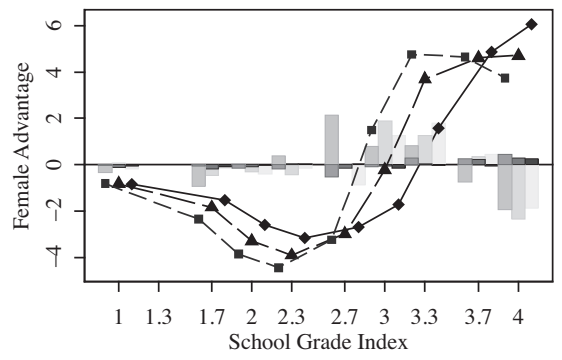

D. Working during School

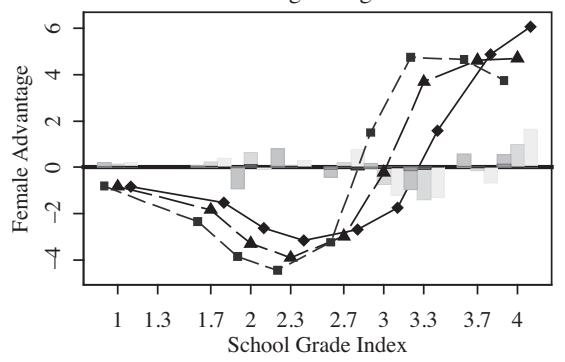

\begin{tabular}{|c|c|c|}
\hline$\longrightarrow$ - 2000-2009: & Composition & Educ. Resp. \\
\hline - $\_-1989-1999:$ & Composition & Educ. Resp. \\
\hline - -t- - 1976-1988: & Composition & Educ. Resp. \\
\hline
\end{tabular}

\section{Figure 5}

\section{Detailed Decomposition of Gender Differences in GPA Levels Among Twelfth Graders}

Notes: Self-reported grades in nine categories (D, C-, C, C+, B-, B, B+, A-, A) are translated into the numbers $1,1.7,2,2.3,2.7,3,3.3,3.7$, and 4 following standard institutional practice. The female advantage represents the gender difference (female minus male) in the percentage of students at each GPA level. The lines in the figure show the raw gender differences; the different shaded bars indicate portions attributable to Composition or Educational Responses effects.

line graphs in Figure 5 show that the female advantage in the percentage of seniors getting As increases from 3.7 percentage points in the 1980s to 4.7 points in the $1990 \mathrm{~s}$ to 6.1 points in the $2000 \mathrm{~s} .{ }^{51}$ At the same time, the male advantage in the $\mathrm{C}+$ grade decreases from 4.4 percentage points in the 1980 s to 3.9 points in the 1990 s to 3.2 points in the 2000s. Thus, for seniors, the changes in gender differentials to be accounted for correspond to 38 percent ( 2.3 percentage points) of the differential in top grades in the 2000 s and to 40 percent (1.3 percentage points) for mediocre grades. The bars for each GPA levels are divided into two, the darker one capturing the composition effects of the factor of interest and the lighter the educational response effects to this factor. In

51. See Tables 5, A4, and A5. These numbers are a bit different from the ones reported in Table 1, Panel B, Row 3 (3.2, 4.4, and 5.4) because, for the analysis, we restrict the sample to those observations for which we have complete data. 
A. Plans for the Future

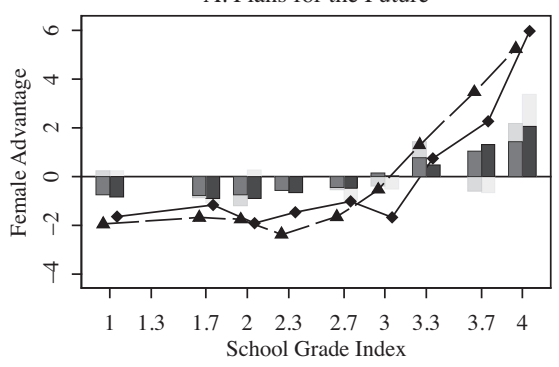

C. Family Background

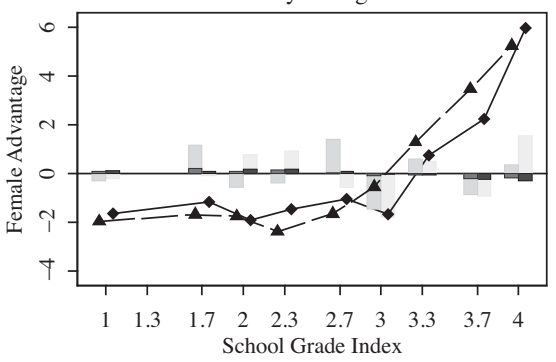

B. Student Attributes

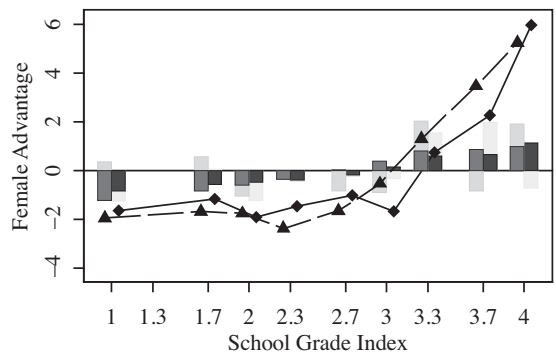

D. Working During School

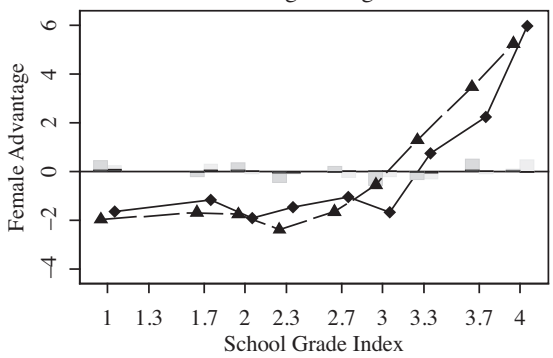

\begin{tabular}{|lll|}
\hline$\longrightarrow$ 2000-2009: & Composition & Educational Responses \\
$\longrightarrow \longleftarrow-1991-1999:$ & Composition & Educational Responses \\
\hline
\end{tabular}

\section{Figure 6}

Detailed Decomposition of Gender Differences in GPA Levels Among Eighth Graders Notes: Self-reported grades in nine categories (D, C-, C, C+, B-, B, B+, A-, A) are translated into the numbers $1,1.7,2,2.3,2.7,3,3.3,3.7$, and 4 following standard institutional practice. The female advantage represents the gender difference (female minus male) in the percentage of students at each GPA level. The lines in the figure show the raw gender differences; the different shaded bars indicate portions attributable to Composition or Educational Responses effects.

some instances, either effect can be negative, as explained above. ${ }^{52}$ Panels A and B show the two most important categories of factors: Plans for the Future (includes type of high school program and educational expectations) and Student Attributes (race, SMSA, smoking and binging, school ability, and misbehavior where available). Panels $\mathrm{C}$ and $\mathrm{D}$ focus on Family Background and Working during School.

The overall message emerging from Figures 5 and 6 is the same as the one we took away from Table 5. The effects of "Plans for the Future" displayed in Panel A are by far the most important explanatory factors contributing to both the composition and educational response effects, generally with the right signs, except for the very low GPA levels. More girls than boys are aiming for professions that require a graduate degree, more girls are getting As. More boys than girls are aiming for skilled worker jobs

52. The distance between the height of the bars and the symbol on the line corresponds to the portion of the gender differential accounted for by other factors. 
and protective service occupations, more boys are getting $\mathrm{C}+\mathrm{s}$. This message is even stronger among eighth graders. The composition effects associated with plans for the future are generally accounting for more than 50 percent of the gender differentials, both at the low and high end of the GPA distribution. For these younger students, plans after high school are arguably further in the future and thus less likely endogenous (in the sense of resulting from cognitive dissonance issues). That is, youth with lower GPA are less likely to say that they will not go to college because of their lower GPA, given that many believe that there is still time for improvement. For eighth graders, Figure 6 shows in Panel B that students' attributes are a nonnegligible set of factors. They include smoking and alcohol binging as well as school misbehavior, which accounts for a sizeable share of the gender differentials at lower GPA levels.

Figure 6 illustrates that relatively little is left to be explained by the family environment once plans for the future and aptitude are included. Worth a mention is the "swimming upstream" phenomenon among high-achieving girls discussed above and some positive educational responses effects to the family environment among boys with $\mathrm{B}$ grades (and with $\mathrm{C}$ grades among seniors). Working during school is less frequent among eighth graders and has a negligible effect there. Among seniors, it bolsters high-achieving girls while keeping more boys in the B grades, but these effects are very small.

In summary, the decomposition results show a marked improvement, over the three time periods, in the model's ability to account for gender differences in academic achievement. This is essentially due to the increasing explanatory power of gender differences in "plans for the future" and applies equally well to Grade 12 and Grade 8 students. Indeed, when the expectation variables are omitted, we can account for relatively little of the gender differences. ${ }^{53} \mathrm{~A}$ startling finding here is that the explanatory power of the educational expectations is as great for eighth graders as it is for twelfth graders. To the extent that educational expectations of eighth graders are less likely endogenous with respect to GPA levels than those of seniors, this is welcome news for the validation of the model. Certainly among twelfth graders, Specification 2, which controls for subjective school ability and educational aspirations, grants less explanatory power to the model, but this does not diminish the relative importance of educational expectations. Indeed, the opposite is true.

\section{Conclusion}

Using a long-lived series of detailed cross-sectional surveys of high school students, this paper sets out to determine which factors among a set of plausible suspects - plans for the future, noncognitive traits, family environment, and labor market work during school - are relatively more important in accounting for changes over the past three decades in the gender achievement gap, especially at the top of the GPA distribution. By comparison with other studies that simply focus on going to college, we are able to distinguish better the drivers of the academic achievement

53. Detailed results are available upon request. To give an example, while Specification 1 allows us to account for more than a third of the gender differences in As (2.4 out of 6.07 points) in the 2000s among twelfth graders (Table 4a). Without the expectations variables, this is reduced to 0.81 points. 
of boys and girls because of the full range of post-secondary options available in our data, from serving in the army, to attending a vocational school, a two-year college, a four-year college and even graduate or professional schools. Indeed, most of the identification of the effect of educational expectations comes from either the two-year college or the graduate school options. Wanting to "go to college" is simply too common an aspiration to be informative.

Our findings show that the predominance of girls at the top of the GPA distribution can be accounted for by their higher educational expectations, themselves linked to career plans that include a graduate degree (such as a law or medical degree). In the 2000s, "Plans for the Future" is the most important set of explanatory factors accounting for the girls' higher share of As at both twelfth and eighth grade levels. These factors are important enough to account for all of the increase of 2.3 percent, from the 1980s to 2000s, in the percentage gender difference of seniors earnings As.

By comparison with girls, more boys think that they are likely to enter military service or to attend a vocational school. Because the career plans of boys include more predominantly male occupations (craftsmen, protective service and military service occupations, engineers, and architects) that do not require advanced degrees, their lower share of high grades is consistent with a threshold model where students economize effort to reach an educational goal.

In an era where much emphasis for improving students' achievement is placed on schools and teachers, this paper offers a longer term view that highlights the role of students' motivation and gender differences therein. Among eighth graders, our second dominant factor accounting for the lower grades of boys is a measure of the frequency of having been sent to the office or to detention over the previous year. This suggests that motivation and misbehavior may go hand-in-hand.

\section{References}

Algan, Yann, Cahuc, Pierre, and Shleifer, Andrei. 2013. "Teaching Practices and Social Capital." American Economic Journal: Applied Economics 5(3):189-210.

Angrist, Joshua D., and William N. Evans. 1998. "Children and Their Parents' Labor Supply: Evidence from Exogenous Variation in Family Size." American Economic Review 88(3): 450-77.

Autor, David, and Wasserman, Melanie. 2013. "Wayward Sons: The Emerging Gender Gap in Labor Markets and Education." Third Way Report. Washington D.C.

Bachman, Jerald G., Patrick M. O’Malley, John E. Schulenberg, Lloyd D. Johnston, Alison L. Bryant, and Alicia C. Merline. 2002. The Decline of Substance Use in Young AdulthoodChanges in Social Activities, Roles and Beliefs. Mahwah: Lawrence Erlbaum Association.

Balsaa, Ana I., Laura M. Giuliano, and Michael T. French. 2011. "The Effects of Alcohol Use on Academic Achievement in High School." Economics of Education Review 30(1):1-15.

Becker, Gary S., William H.J. Hubbard, and Kevin M. Murphy. 2010. "The Market for College Graduates and the Worldwide Boom in Higher Education of Women." American Economic Review 100(2):229-33.

Bertrand, Marianne, and Jessica Pan. 2013. "The Trouble with Boys: Social Influences and the Gender Gap in Disruptive Behavior." American Economic Journal: Applied Economics 5(1):32-64.

Bishop, John H. 2006. "Drinking from the Fountain of Knowledge: Student Incentive to Study and Learn - Externalities, Information Problems and Peer Pressure." In Handbook of the 
Economics of Education, Volume 2, ed. Erik Hanushek and Finnis Welch, 909-44. Amsterdam: Elsevier-North Holland.

Buchmann, Claudia, and Thomas A. DiPrete. 2006. "The Growing Female Advantage in College Completion: The Role of Family Background and Academic Achievement." American Sociological Review 71(4):515-41.

Cameron, Stephen V., and James J. Heckman. 2001. "The Dynamics of Educational Attainment for Black, Hispanic, and White Males." Journal of Political Economy 109(3):455-99.

Card, David, Abigail A. Payne, and Cristina Sechel. 2011. Understanding the Gender Gap in University Participation: An Exploration of the Application Behaviour on Ontario High School Students. Toronto: Higher Education Quality Council of Ontario.

Charles, Kerwin K., and Ming-Ching Luoh. 2003. "Gender Differences in Completed Schooling." Review of Economics and Statistics 85(3):559-77.

Cho, Donghun. 2007. "The Role of High School Performance in Explaining Women's Rising College Enrollment." Economics of Education Review 26(4):450-62.

Conley, Dalton, and Rebecca Glauber. 2006. "Parental Educational Investment and Children's Academic Risk: Estimates of the Impact of Sibship Size and Birth Order from Exogenous Variation in Fertility." Journal of Human Resources 41(4):722-37.

Conley, Dalton, and Mark C. Long. 2010. "Why Are Men Falling Behind? Explanations for the Gender Gap in College." Annals of the American Academy of Political and Social Science 627(1):184-214.

Cornwell, Christopher, David Mustard, and Jessica Van Parys. 2013. "Noncognitive Skills and the Gender Disparities in Test Scores and Teacher Assessments: Evidence from Primary School." Journal of Human Resources 48(1):236-64.

Dahl, Gordon B., and Enrico Moretti. 2008. "The Demand for Sons." Review of Economic Studies 75(4): 1085-120.

Dee, Thomas. 2005. “A Teacher Like Me: Does Race, Ethnicity, or Gender Matter?” American Economic Review Papers and Proceedings 95(2):158-66.

DiNardo, John, Nicole M. Fortin, and Thomas Lemieux. 1996. "Labor Market Institutions and the Distribution of Wages, 1973-1992: A Semiparametric Approach.” Econometrica 64(5):1001-46.

Duckworth, Angela L., and Martin E.P. Seligman. 2006. "Self-Discipline Gives Girls the Edge: Gender in Self-Discipline, Grades, and Achievement Test Scores." Journal of Educational Psychology 98(1):198-208.

Dustmann, Christian. 2004. "Parental Background, Secondary School, Track Choice, and Wages." Oxford Economic Papers 56(2):209-30.

Ford, Reuben. 2012. "Early High School Interventions to Increase Students' Access to PostSecondary Education: Experimental Impacts from Canada's Future to Discover Project." Paper presented at the Conference on Improving Education through Accountability and Evaluation, Rome, October 2012.

Fortin, Nicole M. 2006. "Higher Education Policies and the College Premium: Cross-State Evidence from the 1990s." American Economic Review 96(4):959-87.

Fortin, Nicole M., Thomas Lemieux, and Sergio Firpo. 2011. "Decomposition Methods." In Handbook of Labor Economics, Volume 4A, ed. Orley Ashenfelter and David Card, 1-102. Amsterdam: North-Holland.

Fortin, Nicole M., Philip Oreopoulos, and Shelley Phipps. 2013. "Leaving Boys Behind: Gender Disparities in High Educational Achievement." NBER Working Paper 19331.

Frenette, Marc, Claudia Nicholson, Isaac Kwakye, Taylor S.W. Hui, Judith Hutchison, Sabina Dobrer, Heather Smith Fowler, and Sophie Hébert. 2012. "Future to Discover (FTD) - PostSecondary Impacts Report." Ottawa: Social Research and Demonstration Corporation.

Goldin, Claudia, and Lawrence F. Katz. 2002. "The Power of the Pill: Oral Contraceptives and Women's Career and Marriage Decisions.” Journal of Political Economy 110(1):730-70. 
Goldin, Claudia, and Ilyana Kuziemko. 2006. "The Homecoming of American College Women: The Reversal of the College Gender Gap." Journal of Economic Perspectives 20(4):133-56.

Herbert, Jennifer, and Deborah Stipek. 2005. "The Emergence of Gender Differences in Children's Perceptions of Their Academic Competence." Applied Developmental Psychology 26(3):276-95.

Ingels, Steven J., Ben W. Dalton, and Laura LoGerfo. 2008. "Trends Among High School Seniors, 1972-2004.” NCES Report 2008-320. National Center for Education Statistics, U.S. Department of Education.

Jacob, Brian A. 2002. "Where the Boys Aren't: Non-Cognitive Skills, Returns to School and the Gender Gap in Higher Education." Economics of Education Review 21(6):589-98.

Jacob, Brian A., and Tamara Wilder. 2012. "Educational Expectations and Attainment." In Whither Opportunity? Rising Inequality and the Uncertain Life Chances of Low-Income Children, ed. Greg J. Duncan and Richard J. Murnane, 133-64. New York: Russell Sage Press.

LoGerfo, Laura, Austin Nichols, and Duncan Chaplin. 2006. Gender Gaps in Math and Reading Gains During Elementary and High School by Race and Ethnicity. Washington D.C.: The Urban Institute.

Machin, Steve, and Sarah McNally. 2005. "Gender and Student Achievement in English Schools." Oxford Review of Economic Policy 21(3):357-72.

Perkins, Robert, Brian Kleiner, Stephen Roey, and Janis Brown. 2004. "The High School Transcript Study: A Decade of Change in Curricula and Achievement, 1990-2000.” NCES Report 2004-455. National Center for Education Statistics, U.S. Department of Education.

Reynolds, John R., and Jennifer Pemberton. 2001. "Rising College Expectations Among Youth in the United States: A Comparison of the 1979 and 1997 NLSY." Journal of Human Resources 36(4):703-26.

Stange, Kevin M. 2012. "An Empirical Investigation of the Option Value of College Enrollment." American Economic Journal: Applied Economics 4(1):49-84.

Stinebrickner, Todd, and Ralph Stinebrickner. 2012. "Learning About Academic Ability and the College Dropout Decision." Journal of Labor Economics 30(4):707-48.

Vincent-Lancrin, Stéphan. 2008. "The Reversal of Gender Inequalities in Higher Education: An On-Going Trend" In Higher Education to 2030, Volume 1: Demography, 265-298. OECD Centre for Educational Research and Innovation.

Zafar, Basit. 2011. "How Do College Students Form Expectations?" Journal of Labor Economics 29(2):301-48. 